\title{
On the Structure of the Lower Troposphere in the Summertime Stratocumulus Regime of the Northeast Pacific
}

\author{
Bjorn Stevens,* Anton BeljaArs, ${ }^{+}$Simona Bordoni,* Christopher Holloway,* \\ Martin Köhler, ${ }^{+}$Steven Krueger, \# Verica Savic-Jovcic,* and Yunyan Zhang* \\ * Department of Atmospheric and Oceanic Sciences, University of California, Los Angeles, Los Angeles, California \\ + European Centre for Medium-Range Weather Forecasts, Reading, United Kingdom \\ \# Department of Meteorology, University of Utah, Salt Lake City, Utah
}

(Manuscript received 30 June 2005, in final form 26 January 2006)

\begin{abstract}
Data collected in situ as part of the second field study of the Dynamics and Chemistry of Marine Stratocumulus field program are used to evaluate the state of the atmosphere in the region of field operations near $30^{\circ} \mathrm{N}, 120^{\circ} \mathrm{W}$ during July 2001 , as well as its representation by a variety of routinely available data. The routine data include both the 40-yr European Centre for Medium-Range Weather Forecasts (ECMWF) Re-Analysis (ERA-40) and NCEP-NCAR reanalyses, forecasts from their respective forecast systems (the Integrated and Global Forecast Systems), the 30-km archive from the International Satellite Cloud Climatology Project (ISCCP), the Quick Scatterometer surface winds, and remotely sensed fields derived from radiances measured by the Tropical Rainfall Measuring Mission (TRMM) Microwave Imager (TMI), the Advanced Microwave Sounding Unit, and the Advanced Very High Resolution Radiometer. The analysis shows that outside of the boundary layer the state of the lower troposphere is reasonably represented by the reanalysis and forecast products, with the caveat of a slight warm bias at 850 $\mathrm{hPa}$ in the NCEP-NCAR products. Within the planetary boundary layer (PBL) the agreement is not as good: both the boundary layer depth and cloud amount are underpredicted, and the boundary layer temperature correlates poorly with the available data, which may be related to a poor representation of SSTs in this region of persistent cloud cover. ERA-40 also suffers from persistently weak zonal winds within the PBL. Among the satellite records the ISCCP data are found to be especially valuable, evincing skill in both predicting boundary layer depth (from cloud-top temperatures and TMI surface temperatures) and cloud liquid water paths (from cloud optical depths). An analysis of interannual variability (among Julys) based on ERA-40 and the 1983-2001 ISCCP record suggests that thermodynamic quantities show similar interannual and synoptic variability, principally concentrated just above the PBL, while dynamic quantities vary much more on synoptic time scales. Furthermore, the analysis suggests that the correlation between stratocumulus cloud amount and lower-tropospheric stability exhibits considerable spatial structure and is less pronounced than previously thought.
\end{abstract}

\section{Introduction}

Of the varied cloud regimes, stratocumulus has long been recognized as important to climate. Hence there is a pressing interest in understanding how its climatology responds to subtle environmental changes. By sampling over a variety of conditions, episodic field campaigns could, in principle, provide insight into processes deter-

Corresponding author address: Bjorn Stevens, Department of Atmospheric and Oceanic Sciences, University of California, Los Angeles, 405 Hilgard Ave., Box 951565, Los Angeles, CA 900951565.

E-mail: bstevens@atmos.ucla.edu

DOI: 10.1175/MWR3427.1

(C) 2007 American Meteorological Society mining how stratocumulus evolve on climatic scales. In practice, however, differences among the specific goals and strategies of varied field campaigns make it difficult to use these data in this manner. As a result, most studies of the longer-term evolution of stratocumulus depend on what we call routine data; namely, data that more uniformly span longer space and time scales. Examples include surface observer networks (Norris 1998), historical data from weather ships, routine radiosonde data, products derived from the reanalysis of meteorological data, or retrievals of the atmospheric state from satellite-measured radiances.

An example of the use of routine data in these respects are the analyses of soundings and cloud obser- 
vations from Ocean Weather Ship (OWS) $\mathrm{N}^{1}$ that have framed our understanding of the climatology of stratocumulus (Klein and Hartmann 1993; Klein 1997; Norris and Klein 2000). The finding that about two-thirds of the interannual variance in low cloud amount above OWS $\mathrm{N}$ could be explained by variations in the lowertropospheric stability (as measured by the difference between the $700 \mathrm{hPa}$ and surface potential temperatures) has served as a basis for parameterizing stratocumulus in a number of models (e.g., Boville et al. 2006; Miller 1997) and is central to some hypotheses of how clouds may respond to climatic changes (Miller 1997).

Although routine observations from weather ships terminated at the dawn of the satellite record, we now have been retrieving meteorological records from radiances measured by satellites for more than $25 \mathrm{yr}$, a period that is just longer than the period of weather ship service. These data, particularly because they have extensive spatial and temporal coverage [e.g., the International Satellite Cloud Climatology Project (ISCCP); Rossow and Schiffer (1999)], offer exciting opportunities to study how cloud regimes behave on interannual time scales and longer. Opportunities for new empirical insights are only compounded when such data can be combined with increasingly sophisticated reanalyses and shorter records from a wider diversity of satellites. Examples of these types of approaches being applied to stratocumulus include the recent study by Wood and Bretheron (2004), wherein satellite and reanalysis data were elegantly combined to infer the variation of stratocumulus entrainment over large scales, as well as the study by Rozendall and Rossow (2003) that investigated the modes of variation of stratiform clouds based on ISCCP data.

However, unlike the weather ship data, which directly measures the state of the lower troposphere above the weather ship, the state of the lower troposphere in the reanalysis, or as retrieved from satellite radiances, is inferred by complicated and uncertain procedures. As a result, the information content of some routine datasets is not transparent. This is particularly true in remote regions such as the stratocumulus areas, where there is a relative paucity of in situ data, thereby leading to fewer constraints on the reanalysis procedures or retrieval algorithms. Although different remote sensing products are validated individually and reanalysis products are given intense scrutiny, explorations of the extent to which routine data products can be combined to give a more or less complete descrip-

\footnotetext{
${ }^{1}$ OWS $\mathrm{N}$ was positioned at $30^{\circ} \mathrm{N}, 140^{\circ} \mathrm{W}$ near the edge of the stratocumulus regime over the northeast Pacific.
}

tion of the structure of the lower troposphere in regions where stratocumulus predominate are less common. Toward these ends, in situ data from episodic field studies can be quite useful and motivate this study.

Given the routine data, as embodied by the available reanalysis, satellite, and monitoring data over the remote marine environment sampled during the second field study of the Dynamics and Chemistry of Marine Stratocumulus (DYCOMS-II; Stevens et al. 2003b), we ask the following question: how well could we have inferred the basic state of the lower troposphere had we not been there to measure it directly? To the extent that routine data products provide an adequate representation of the lower troposphere observed during DYCOMS-II, we can begin to explore broader questions more directly related to the interplay of stratocumulus and climate, such as to what extent were conditions during DYCOMS-II typical of past years? Or, to what extent is the interannual variability of data records that reproduced the DYCOMS observations consistent with past studies?

We begin by reviewing the routine and aircraft data collected as part of DYCOMS-II, which form the basis of our comparison in section 2. Section 3 uses these data to qualitatively characterize the basic structure and variability of the lower troposphere through the course of July 2001. The quantitative evaluation of the routine data is performed in section 4 . In section 5 we explore the structure of the subset of routine data that we find most useful on larger space and time scales, in part to place the DYCOMS-II observations in some larger context, but also to begin answering some of the ancillary questions stated above. A discussion of our results follows in section 6 , while section 7 recapitulates our major findings.

\section{Methods and data}

\section{a. Flight strategies and study region}

The basic study region corresponds to a box defined by the DYCOMS-II flights. In Fig. 1 this box is overlaid on a map that also shows the mean visible reflectivity for 7-28 July as given by the ISCCP DX data product. Crosses denote the mean positions of the aircraft sampling for 10 research flights. Usually only nine of the DYCOMS-II flights are called research flights, but here we also incorporate data from a tenth flight. This flight, corresponding to the most northward marker, was flown at the end of the study, and was a daytime mission of about half the duration of the other flights, most of which were nocturnal. Further information about all of the flights is given in Table 1 and the electronic supplement of Stevens et al. (2003a). Flights are iden- 


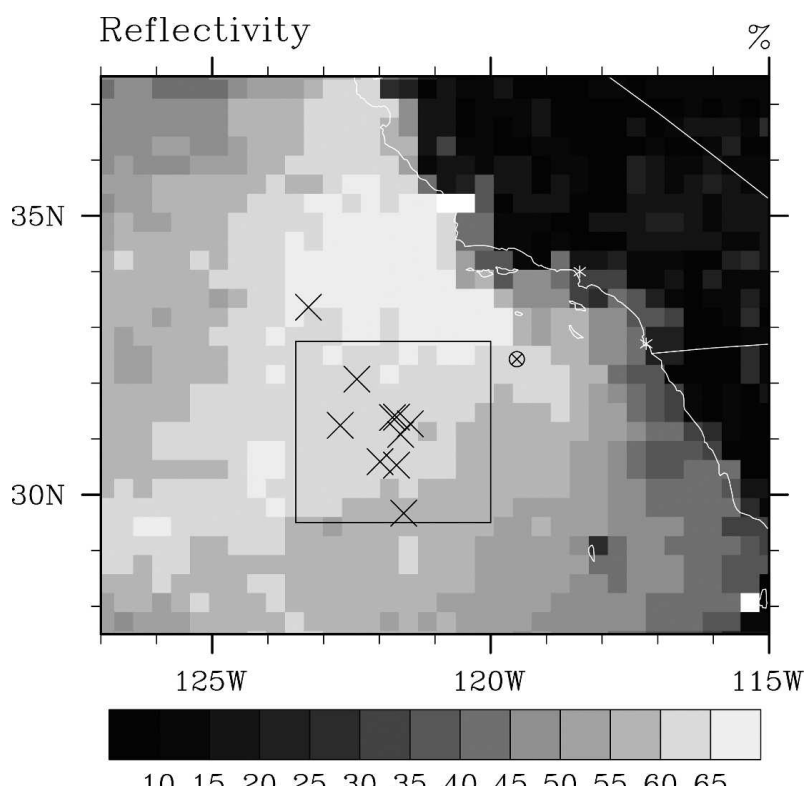

FIG. 1. The analysis area is shown boxed over the mean 1500 2100 UTC (0800-1400 PDT) visible reflectivity from the ISCCP DX data. Centers of flight operations for each of the 10 flights are shown by the crosses. The position of the nearest monitoring buoy is shown by the circled cross.

tified on the basis of their sampling strategy. The seven entrainment flights comprised pairs of $30 \mathrm{~min}(\approx 60-\mathrm{km}$ diameter) circles flown in alternating directions drifting with the mean wind at five different levels: (i) $100 \mathrm{~m}$ above the surface; (ii) near the top of the subcloud layer, but everywhere below the cloud base insofar as it was well defined; (iii) near, but everywhere above, the cloud base; (iv) near the cloud top at a level chosen to almost always remain in the cloud; and (v) at some level in the free troposphere above the cloud top. One of the free-tropospheric circles was always flown at the beginning of the on-station time, another at the end. These were useful for probing the structure and height of the cloud top with a downward-looking aerosol backscatter lidar and for dropping sondes (typically four were dropped at regular intervals around the circle) to probe the mean boundary layer structure. Because of the limited utility of nighttime satellite imagery, the lack of ambient moonlight, ${ }^{2}$ and logistical constraints, both the choice of flight days and target areas could not be biased toward particular features. Although this constrained field operations, it produced a dataset well suited to the type of investigation we attempt here.

\footnotetext{
${ }^{2}$ The new moon was on 20 July, within 10 days of both the start and end of flight operations.
}

TABLE 1. Summary of DYCOMS-II flights.

\begin{tabular}{cccccl}
\hline \hline Flight & Lat & Lon & $\begin{array}{c}\text { Takeoff DD } \\
(\text { HHMM })\end{array}$ & Duration & $\begin{array}{c}\text { Sampling } \\
\text { strategy }\end{array}$ \\
\hline 1 & 31.3 & 121.7 & $10(0601)$ & $9.3 \mathrm{~h}$ & Entrainment \\
2 & 31.4 & 121.7 & $11(0624)$ & $9.5 \mathrm{~h}$ & Entrainment \\
3 & 31.0 & 121.6 & $13(0618)$ & $9.5 \mathrm{~h}$ & Entrainment \\
4 & 29.7 & 121.5 & $17(0622)$ & $9.2 \mathrm{~h}$ & Entrainment \\
5 & 30.5 & 121.7 & $18(0619)$ & $9.4 \mathrm{~h}$ & Entrainment \\
6 & 30.6 & 122.0 & $20(0539)$ & $9.6 \mathrm{~h}$ & Other \\
7 & 31.3 & 121.4 & $24(0553)$ & $9.9 \mathrm{~h}$ & Entrainment \\
8 & 32.1 & 122.4 & $25(1945)$ & $9.6 \mathrm{~h}$ & Entrainment \\
9 & 31.2 & 122.7 & $27(1816)$ & $9.5 \mathrm{~h}$ & Other \\
10 & 33.4 & 123.3 & $28(1948)$ & $4.3 \mathrm{~h}$ & Other \\
\hline
\end{tabular}

\section{b. Aircraft data}

Our primary source of information into the actual state of the lower troposphere (truth) is the aircraft data, which we attempt to use as extensively as possible. In particular, the state of the atmosphere is deduced from aircraft-based measurements of air temperature, humidity, liquid water, static pressure, and local wind speed. For most of these quantities redundant measurements are available (i.e., three temperature probes, various humidity probes capable of measuring at high and low rate, and a variety of liquid water sensors) from which the most reliable estimates are culled as part of the data quality evaluation performed by scientists and technicians working with the Research Aviation Facility at National Center for Atmospheric Research (NCAR). In some cases, however, we use nonstandard measurements, or standard measurements in nonstandard ways. These cases, and cases where the standard use of standard measurements is deemed unreliable, or needing clarification, are discussed further below.

For instance, a critical quantity characterizing the state of the stratocumulus-topped boundary layer (STBL) is its depth $z_{i}$, which we equate with the base of the temperature inversion. On the seven entrainment flights, estimates of $z_{i}$ are derived from both the dropsondes and downward-looking lidar measurements. For the former, the STBL depth is taken from the mean of the inversion base as calculated from each sounding within a group (of typically four) dropped on a particular circular flight leg. In the latter, cloud top is unambiguously evident at 1-s intervals. This measurement allows estimates of spatial variability that we present using the $2 \sigma$ range centered on the lidar mean, where $\sigma$ denotes the standard deviation in cloud-top height detected in this fashion. On the three nonentrainment flights, $z_{i}$ is estimated from all of the available (typically half a dozen) aircraft soundings.

Sea surface temperatures (SSTs) are measured using 
a downward-looking Heimann KT 19.85 pyrometer. Its measurement is based on radiation in the 9.6-11.5- $\mu \mathrm{m}$ range, and its stated resolution is approximately $1^{\circ} \mathrm{C}$. To minimize the effects of radiation from the ambient water vapor we base our estimates on those data collected during periods for which the aircraft was below $200 \mathrm{~m}$. The low-level flight leg, which mostly satisfies this criterion, tended to be biased toward the end of our on-station time, near sunrise, when the ambient light made it safer to fly at very low levels. Because flight tracks tended to drift over warmer water following the mean flow, one expects the sunrise SST to be slightly warmer than the flight-mean SST. Such a warm bias is probably compounded by "sky effects" caused by the reflection of downward IR radiation, which we did not attempt to correct for and which, because of the low cloud bases, were likely to be nonnegligible.

Because we have no in situ estimates of cloud liquid water path $L$, we estimate $L$ based on flight-averaged cloud thicknesses and a mean liquid water lapse rate $\Gamma_{l}=1.5 \mathrm{~g} \mathrm{~kg}^{-1} \mathrm{~km}^{-1}$. The former is taken from vanZanten et al. (2005) when available and using a sounding composited from all the flight data otherwise, while the latter is based on differences in liquid water content in the cloud-top versus cloud-base circles for the seven entrainment flights, and is not corrected for cloud fraction (which in any case was very near unity for all flights).

Divergences are estimated using the method outlined by Savic-Jovcic et al. (2002), and are averaged over all the clockwise and counterclockwise circle pairs flown within the STBL. Because estimates of the divergence are based on the circular flight tracks, they are only available for entrainment flights. To eliminate biases associated with uncertainty in the mean attack angle offset, this method assumes that the mean pitch of the air motion sensing system is zero (D. H. Lenschow 2005, personal communication). Errors are estimated based on the variance among estimates from individual circles.

Because the calibration procedure for the aircraft winds assumes small values of aircraft pitch and roll, we mask as missing value any times for which the aircraft roll exceeded $\pm 3^{\circ}$ of its mean value, or the pitch was larger than $\pm 2^{\circ}$. This excludes sharp climbs, descents, and turns from this analysis, but results in a nearly negligible data reduction. Although estimates of the mean winds can be affected by heading biases, flight tracks during DYCOMS-II were designed to minimize such effects. Estimates of temperature and humidity are not thought to suffer from aircraft orientation relative to the airflow, and thus are not filtered in any way.

The STBL was remarkably well mixed for all flights, certainly to the point where differences between the top and bottom of the STBL were less than differences across a flight circle. For this reason we average over all the data collected within the STBL to report a single estimate of an STBL state variable. The $2 \sigma$ variation that often accompanies our presentation of the mean values is best interpreted as the true variability sampled in the atmosphere. Integral scales for horizontal winds, moisture, and temperature tend to range between 1 and $10 \mathrm{~km}$. Given that each flight traversed thousands of kilometers (albeit in circles), the uncertainty in our estimate of the mean from the aircraft data is much less than the intrinsic variability of the system.

\section{c. Satellite measurements}

We make use of satellite data from a variety of sources: cloud climatological data is taken from the ISCCP DX archive; the Quick Scatterometer (QuikSCAT) provides estimates of surface winds on a $25-\mathrm{km}$ grid; the Tropical Rainfall Measurement Mission (TRMM) Microwave Imager (TMI) provides estimates of column water vapor and liquid, as well as surface wind speeds and sea surface temperatures on a $0.25^{\circ}$ grid; the Advanced Microwave Sounding Unit (AMSUA) aboard the National Oceanic and Atmospheric Administration (NOAA) satellite, NOAA-15, provides secondary estimates of column water vapor and liquid. In addition we investigated sea surface temperatures from the Advanced Very High Resolution Radiometer (AVHRR) and precipitation from the blended Global Precipitation Climatology Product (GPCP). These latter two measurements both yielded very little information: persistent cloud cover meant that AVHRR SSTs were only available about $5 \%$ of the time, and little or no precipitation was evident in the GPCP analysis over the study region. Unless otherwise noted, the satellite data are analyzed over the study region indicated in Fig. 1. Except for the ISCCP data, which we discuss below, details pertaining to the data quality, sampling, and spatial coverage of these sensors are given in appendix A.

The ISCCP DX product is provided satellite-bysatellite on roughly a $30-\mathrm{km}$ scale at 3-hourly intervals from July 1983. We incorporate data through August 2001. Navigated pixels from the ISCCP record are mapped to a $1 / 3^{\circ}$ grid using a nearest-neighbor algorithm. Cloud-top temperature data is available for all of the times, while optical depths and reflectivities are available only for the daylight hours. We estimate the cloud liquid water path from the optical depth $\tau$ using the relationship $L=2 / 3 \tau / r_{e}$ (e.g., Stephens 1978), where $r_{e}$ is the effective radius, which we fix at the ISCCP default value of $10 \mu \mathrm{m}$. This is consistent with values 
measured on flight days (vanZanten et al. 2005). Cloudtop pressures from the ISCCP product represent a synthesis of atmospheric soundings derived from the Television Infrared Observation Satellite Operational Vertical Sounder and, because of biases in the latter, tend to be underestimated (Wang et al. 1999). To avoid this problem we estimate cloud-top height $z_{i}$ using the D2 method from Wang et al. (1999) which specifies $z_{i}=$ $\left(T_{c}-T_{s}\right) / \Gamma$. Here, $T_{c}$ is the ISCCP cloud-top temperature, $T_{s}$ is the surface air temperature, and $\Gamma$ is a temperature lapse rate. For $T_{s}$ we subtract a constant $1 \mathrm{~K}$ offset from the SST to account for the mean air-sea temperature difference observed during DYCOMS-II. Likewise $\Gamma$ is set to its mean value of $8.0 \mathrm{~K} \mathrm{~km}^{-1}$ as observed during DYCOMS-II. This is somewhat larger than the climatological value of $6.5 \mathrm{~K} \mathrm{~km}^{-1}$ suggested by Minnis et al. (1992) but commensurate with the mean lapse rate observed in similar clouds over the northeast Atlantic (Wang et al. 1999) as well as lapse rates inferred by Betts et al. (1992) in an analysis similar to our own.

\section{d. Reanalysis and forecast data}

The reanalysis of meteorological observations is taken from both the first generation reanalysis by the National Centers for Environmental Prediction (NCEP)-NCAR reanalysis (NNRA; Kalnay and Coauthors 1996) and the second-generation product recently made available by the 40-yr European Centre for Medium-Range Weather Forecasts (ECMWF) ReAnalysis (ERA-40; Uppala et al. 2005). The NNRA product is evaluated on a $2.5^{\circ}$ grid at 23 pressure levels. The coarseness of this product complicates a simple comparison over the DYCOMS-II target area, which partially intersects four of the NNRA grid boxes, which in all cover a much broader region. The effect of possible spatial biases on comparisons with NNRA are discussed in the text. Such problems do not arise when evaluating the much finer resolution (effectively $1.1^{\circ}$ ) ERA-40 data. To take advantage of the full ERA-40 resolution we work with the full T159 product, either as provided on 23 pressure levels or on the original 60 model levels. This reanalysis differs substantially from the first generation product by ECMWF [Gibson et al. 1997; the 15-yr ECMWF Re-Analysis (ERA-15)], which was used by Duynkerke and Teixeira (2001) in a study similar to the present one. Specifics of our use of the ERA-40 archive, and further information about the reanalysis, are provided in appendix B and in the overview article by Uppala et al. (2005).

Dropsonde data from the DYCOMS-II research flights were put on the global telecommunication system and, according to the observational coverage charts provided by the ECMWF, were incorporated into the reanalyses, thus potentially leading to more favorable comparisons with the data than may otherwise have been expected. This may limit the extent to which the DYCOMS-II data can be used as an independent test of these products, in part motivating our exploration of the forecast products that did not incorporate sounding information.

Forecast products were also archived for the DYCOMS-II target area for the month of July 2001. Horizontal averages of gridpoint data in the study region and a single gridpoint value valid at $31.08^{\circ} \mathrm{N}, 238.4^{\circ} \mathrm{W}$ were provided by the Integrated Forecast System (IFS) of the ECMWF. For this analysis we focus on the areaaveraged products, which were provided at $60 \sigma$ levels at hourly intervals from the 72-h forecast initializing at 1200 UTC each day. Coincidentally, for this period the IFS was essentially the same (cycle 23r4) as was used by the ECMWF to perform its +40 -yr reanalysis, although the IFS used a T511 four-dimensional variational data assimilation (4DVAR) system versus the T159 3DVAR employed in ERA-40 (Uppala et al. 2005); see also appendix B). NCEP made 48-h forecasts available from their Global Forecast System (GFS), beginning at 0000 UTC. GFS fields were provided at 9 grid points and $40 \sigma$ (model) levels ( 9 of which are below $850 \mathrm{hPa}$ ) over the DYCOMS-II area. Our analysis is based on the average over these gridpoint values.

\section{e. Notation}

Throughout, subscript $s$ denotes values valid at the surface, and subscript $m$ designates values valid in the planetary boundary layer (PBL). For the aircraft data, mixed-layer quantities refer to data averaged over all heights below the base of the temperature inversion, while for reanalysis products, subscript $m$ is synonymous with the $1000-\mathrm{hPa}$ data, this being the only level of the analysis that is almost always within the PBL. Numeric subscripts refer to data valid at a specific pressure level; for instance, $\theta_{850}$ denotes the 850 -hPa potential temperature. Throughout we use $\sigma$ to denote a standard deviation.

\section{Synoptic overview}

Before exploring the fidelity of individual routine data products, we first assemble all of the available data to develop a rough picture of the structure of the lower troposphere, its variability, and larger-scale context. We begin with the cloud field, three examples of which are presented in Fig. 2. These were chosen because they encapsulate many features observed through the course 

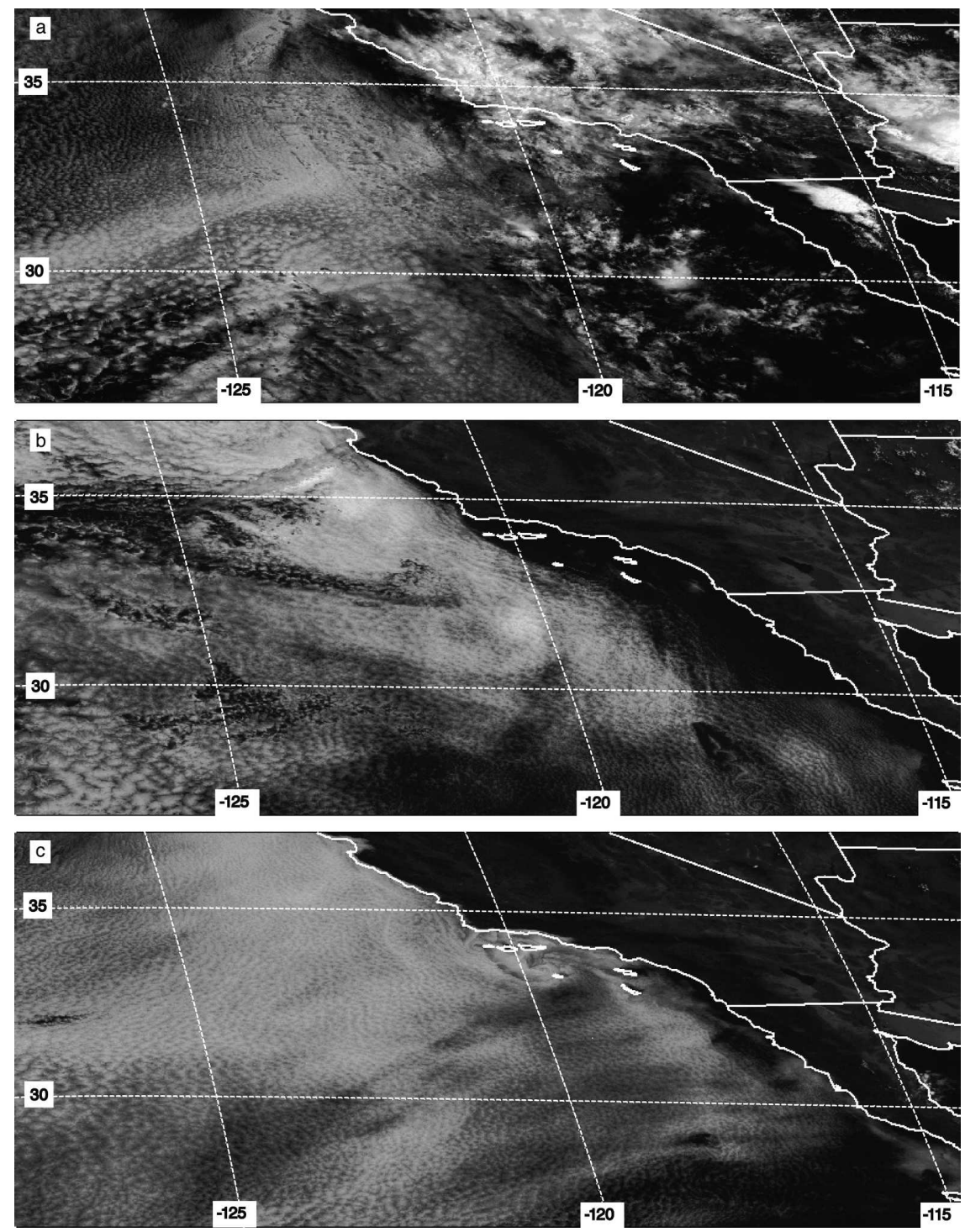

FIG. 2. Channel 1 (visible) reflectivity from GOES-10 at $1800 \mathrm{UTC}$ (a) $6 \mathrm{Jul}$, (b) $12 \mathrm{Jul}$, and (c) $27 \mathrm{Jul}$.

of the month, wherein clouds were persistent but varied in form. Situations in which deeper convection centered over the continent interacted locally with the cloud field in the vicinity of the study region were mostly confined to the beginning of the month. Such a situation is shown in Fig. 2a. Cloud tops over the continent, and in the coastal waters east of $120^{\circ} \mathrm{W}$, extend well above the freezing level, and regions of low-level clouds are pushed off to the west and northwest. Persistent but textured, or varied, cloud fields were perhaps the most common. Such a situation is shown in Fig. 2b, where regions of open cells are evident extending along a line to the northwest; thin, more stratiform, clouds prevail south of this line, and locally clear conditions appear to be associated with flow around, or over, Pt. Conception. A rather more homogeneous cloud field is shown in Fig. 2c. North of $30^{\circ} \mathrm{N}$ this is an example of the "textbook" stratiform cloud layers that were frequent during this month and are expected for this region during this time of year.

Figure 3 more quantitatively summarizes the state of the lower troposphere over the study region through the course of July 2001. Focusing first on the mean conditions, STBL winds (in the second and third panels from the top) were from the north, or northwest, at about $7 \mathrm{~m} \mathrm{~s}^{-1}$, and diverged (top panel) at a rate of about $4 \times 10^{-6} \mathrm{~s}^{-1}$ (the flight mean divergence is biased by the fourth research flight, and is somewhat lower). 

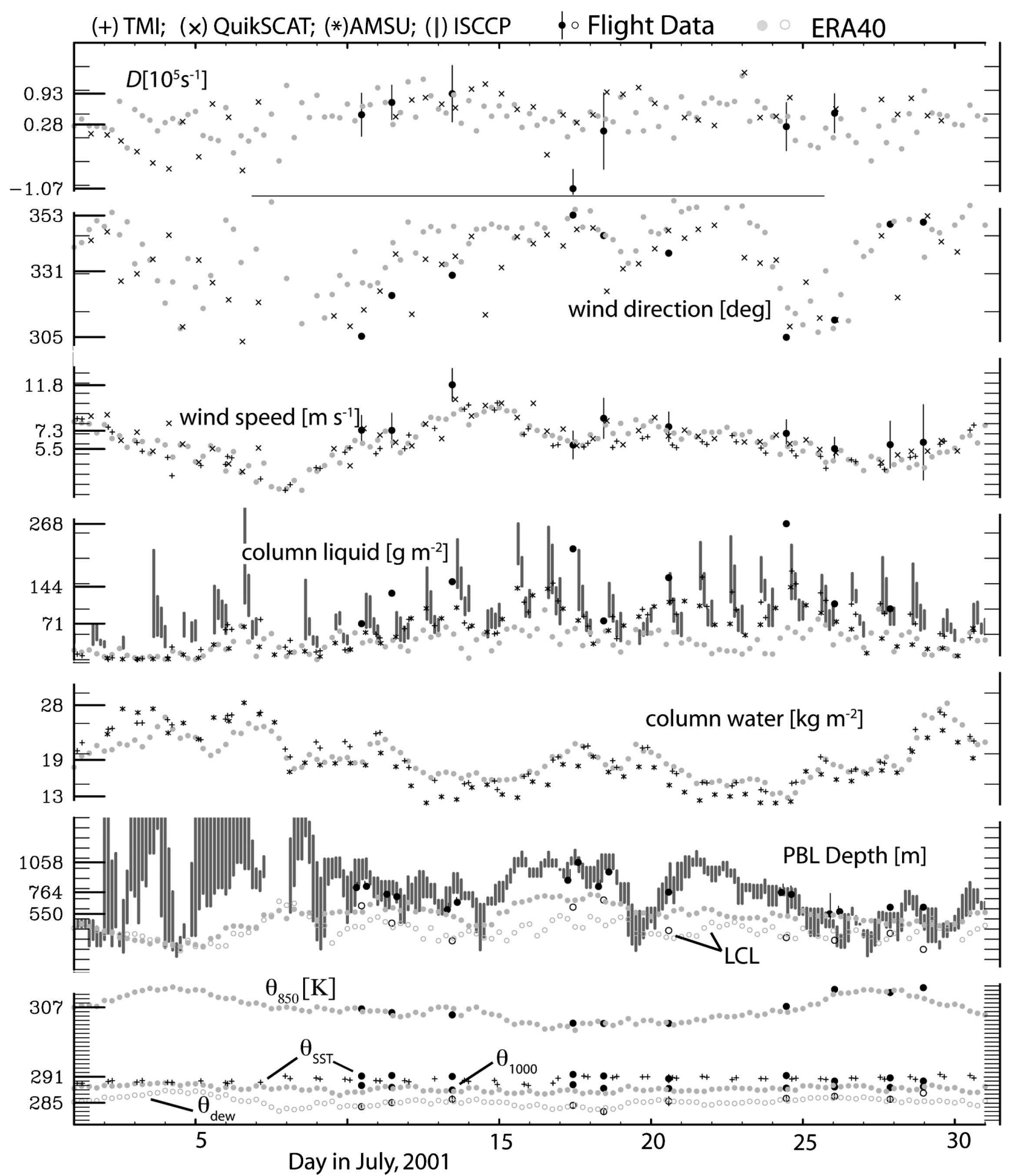

FIG. 3. Synthesis of flight and routine data over the study region for July 2001. Estimates of variability accompany the flight data, (bottom) open circles denote $\theta_{\text {dew }}$, and (second from bottom) open circles denote LCL. For reasons of clarity the NNRA data are not included in this plot. Axis labels minimum, mean, and maximum of flight data. 

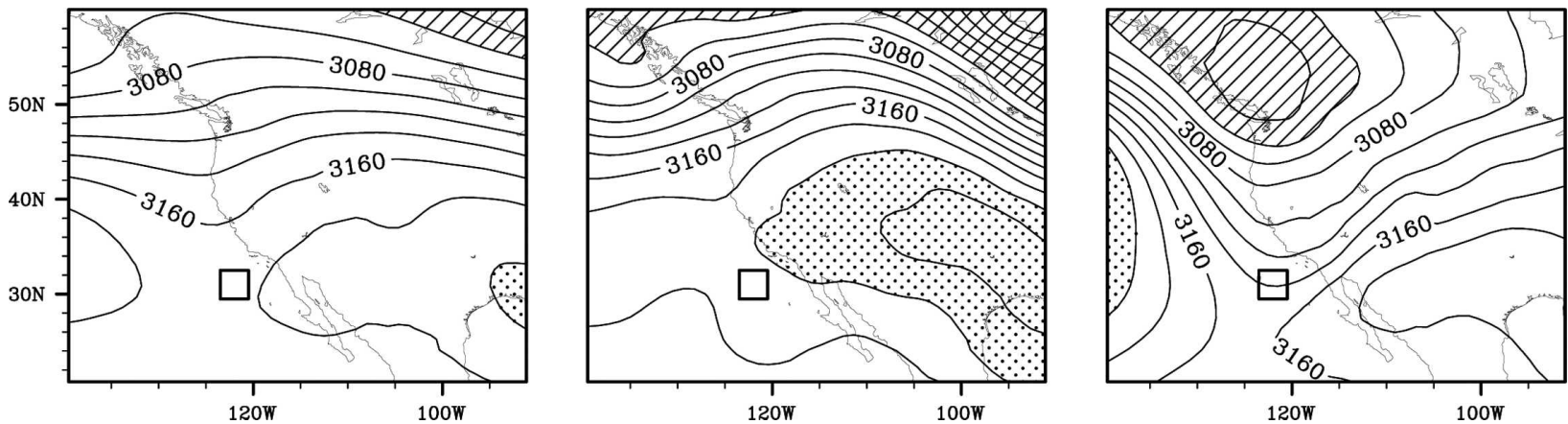

FIG. 4. The 700-hPa geopotential height $z_{700}$ as derived from ERA-40: (left) long-term July climatology, (middle) 3-5 Jul, and (right) 15-17 Jul 2001. Stippling indicates highs $\left(z_{700}>3200 \mathrm{~m}\right)$, hatching indicates lows $\left(z_{700}<3040 \mathrm{~m}\right)$. The contours are every $20 \mathrm{~m}$, and the study region is indicated by the box.

Flight-averaged (i.e., essentially nocturnal) cloud liquid water paths averaged $150 \mathrm{~g} \mathrm{~m}^{-2}$ topping a 750-m-deep STBL. The free-tropospheric thermodynamic state was much warmer and drier, with $\theta_{850}$ and $q_{850}$ (not shown) respectively $306.8 \mathrm{~K}$ and $3.3 \mathrm{~g} \mathrm{~kg}^{-1}$ over the 10 flights. ${ }^{3}$ The sea surface potential temperature, $\theta_{\mathrm{SST}}$, averaged 289.6 K on flight days, implying a lower-tropospheric stability, $\Delta \theta=\theta_{700}-\theta_{s}$, of about $25 \mathrm{~K}$, where $\theta_{s}$ is the potential temperature of the air at the surface. ${ }^{4}$ For this value of $\Delta \theta$ the regression of Klein and Hartmann (1993) predicts cloud amounts of about $84 \%$, almost identical to what was observed. ISCCP cloud incidence was $81 \%$ for the entire month, and $84 \%$ when just averaged over flight days. Within the STBL, $\theta_{l}$ (the liquid water potential temperature) averaged 288.6 K. Flightaveraged dewpoint potential temperatures ${ }^{5}$ imply a mean lifting condensation level (LCL) near $425 \mathrm{~m}$. The extent to which the STBL is colder than both the overlying atmosphere and the underlying ocean reflects the efficacy of cold advection (northerly winds) as well as net radiative cooling.

\footnotetext{
${ }^{3}$ To calculate $q_{850}$ we averaged all the flight data between a level $100 \mathrm{~m}$ above the cloud top and $2610 \mathrm{~m}$, with the latter level chosen so that the mean pressure of the resultant data corresponded to the desired pressure level. Unlike temperature, which tends to vary smoothly and systematically in the vertical, sharp vertical variations in the water vapor field encouraged a more bulk approach in our estimation of it using data collected in situ. An overview of the humidity structure as measured by dropsondes during DYCOMS-II is presented by Wang (2005).

${ }^{4}$ This estimate is based on $\theta_{\mathrm{SST}}$ from TMI offset by $1 \mathrm{~K}$ to account for the mean air-sea temperature difference. To estimate $\theta_{700}$ we use measured values at $850 \mathrm{hPa}$ and the ECMWF mean lapse rate of $6.8 \mathrm{~K}$ between 700 and $850 \mathrm{hPa}$.

${ }^{5}$ The dewpoint temperature $T_{\text {dew }}$ is calculated using the total water-specific humidity and the temperature that air throughout the PBL would have if isentropically brought to the surface pressure. The dewpoint relative potential temperature is then calculated as $T_{\text {dew }}\left(p_{s} / 1000\right)^{0.285}$
}

Although clear patterns of variability emerge only after some study, the beginning and end of the month differentiate themselves from the middle of the month by their tendency to have larger amounts of column water vapor, elevated temperatures in the free troposphere, and shallower boundary layer depths in ERA40. The satellite imagery and surface analyses also show that deep convection is evident over northwestern Mexico during these periods. For instance, in the early period (thunderstorms were reported over San Diego, California, just prior to field operations) deep convection extends northwestward across California and over the ocean in the vicinity of the study region (Fig. 2a). The tendency toward weaker free-tropospheric stability (i.e., a depression in $\theta_{850}$ ), drier air aloft, deeper boundary layers, and more boundary layer cloudiness toward the middle of the month is associated with the weakening of the mid-to-upper-level anticyclone over the western portion of the continent and the increased influence of synoptic troughs passing to the north. This is most evident in association with a strong low pressure system that moved through southwestern Canada during the middle of the month. This system was accompanied by cold advection at $850 \mathrm{hPa}$, and appears to be responsible for the midmonth minimum in $\theta_{850}$ and some further deepening of the boundary layer.

The synoptic situation associated with these changes is evident in the pattern of the $700-\mathrm{hPa}$ geopotential height, which is shown in Fig. 4. The left panel presents the long-term July climatology, which is similar to the average for July 2001; the middle panel shows an average for 3-5 July 2001 when the continental anticyclone was especially dominant; and the right panel depicts the situation averaged over 15-17 July 2001 when the influence of a passing disturbance to the north was most evident over the study region. During periods of troughing, the $700-\mathrm{hPa}$ flow tends to be northwesterly over the target area, as compared with easterly or 
TABLE 2. Mean state summary: averages for the 10 reanalysis times most closely corresponding to midpoint time of each mission.

\begin{tabular}{lrcr}
\hline \hline \multicolumn{1}{c}{ Field } & Flight & ERA-40 & NNRA \\
\hline$\theta_{850}(\mathrm{~K})$ & 306.8 & 306.4 & 308.2 \\
$q_{850}\left(\mathrm{~g} \mathrm{~kg}^{-1}\right)$ & 3.3 & 3.6 & 3.5 \\
$\theta_{m}(\mathrm{~K})$ & 288.6 & 288.0 & 287.8 \\
$q_{m}\left(\mathrm{~g} \mathrm{~kg}^{-1}\right)$ & 9.5 & 9.3 & 9.4 \\
$u_{m}\left(\mathrm{~m} \mathrm{~s}^{-1}\right)$ & 3.4 & 2.3 & 3.5 \\
$v_{m}\left(\mathrm{~m} \mathrm{~s}^{-1}\right)$ & -6.1 & -5.9 & -5.8 \\
$z_{i}(\mathrm{~m})$ & 760 & 514 & - \\
\hline
\end{tabular}

southeasterly during the periods of midlevel anticyclonic dominance, consistent with the changing structure of the lower troposphere as discussed above.

Overall variations in boundary layer structure on monthly time scales appear to be principally modulated by variations aloft. One type of regime is characterized by continental anticyclone dominance, during which the boundary layer is shallower and conditions aloft are warmer, while another features midlatitude dominance associated with deeper boundary layers and cooler, drier conditions aloft. Low-level cloudiness is evident in both regimes, although through the entrainment of more continentally influenced free-tropospheric air the former is more favorable for interactions with the continental aerosol. To the extent that cloud depth is modulated by boundary layer thickness, the latter favors thicker clouds and hence more precipitation.

\section{Routine analysis}

The previous section developed a qualitative picture of the structure of the lower troposphere near $30^{\circ} \mathrm{N}$, $120^{\circ} \mathrm{W}$. Here we focus on the driving question behind our study: to what extent can routine data (i.e., data that is routinely available) quantitatively describe the state of the lower troposphere near $30^{\circ} \mathrm{N}, 120^{\circ} \mathrm{W}$ during July 2001 ?

\section{a. Thermodynamic and dynamic state}

We begin by comparing ERA-40 and NNRA of the thermodynamic and dynamic state of the study region with the flight data for the analysis times closest to flight times. The coarseness of the NNRA is a source of some ambiguity that we tried to resolve by focusing on only those NNRA grid columns that most fully overlapped the study regime. Doing so did not lead to significant improvements, so we maintain our comparison using the NNRA data over the $5^{\circ}$ latitude-longitude box centered at $31.5^{\circ} \mathrm{N}, 121.0^{\circ} \mathrm{W}$, which is somewhat broader than the principal study region indicated in Fig.

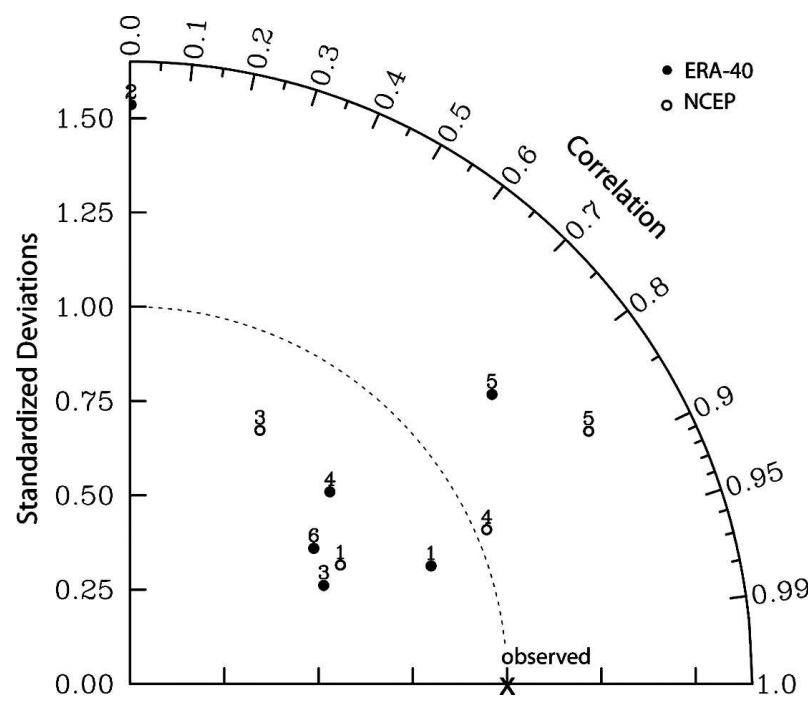

FIG. 5. Taylor diagram illustrating the correspondence between routine (ERA-40 and NNRA) and flight data for $\theta_{850}(1), \theta_{m}(2)$, $q_{m}(3), u_{m}(4), v_{m}$ (5), and PBL depth (6).

1. Table 2 suggests that the reanalysis products are similar in many respects, with ERA-40 better representing the thermal structure of the free troposphere and NNRA better capturing the zonal wind. The single greatest discrepancy between ERA-40 and the flight data is in the representation of $z_{i}$. This field is not available in the NNRA, and is placed roughly $250 \mathrm{~m} \mathrm{(33 \% )}$ shallower by ERA-40 relative to what was observed.

We measure the ability of the reanalyses to capture the variability observed across flights using a Taylor (2001) diagram. In this diagram (Fig. 5) the variation of the routine record standardized by the flight record (observations) is measured by the distance from the origin, and the correlation of the routine record with the flight record is measured by the azimuthal angle in polar coordinates. Doing so results in a plot for which the distance from the observation point, marked by an " $x$ " at the intersection of the unit circle and the horizontal axis, measures the RMS difference between the time series in the case of zero mean bias. From Fig. 5 it is apparent that the correlations between the reanalysis and observational data are generally greater than $70 \%$. Between the two reanalysis products, ERA-40 is slightly superior in most respects, with the exception of $u_{m}$ whose variability is better represented by NNRA. The reanalyses are both deficient in their representation of the variability of the PBL thermal state $\left(\theta_{m}\right)$ for which neither product shows any skill. Lack of skill in representing $\theta_{m}$ may not be too surprising given the small signal: for the 10 research flights, $\sigma_{\theta m}$ is less than $0.4 \mathrm{~K}$. Although small, and less significant than the mean state air-sea temperature difference biases, vari- 
ability of this magnitude can also be important both for radiative and surface coupling processes. A decrease in $\theta_{m}$ of $0.4 \mathrm{~K}$ reduces the air-sea thermal contrast by more than $20 \%$ and lowers cloud base by $50 \mathrm{~m}$, which can be substantial for clouds whose mean thickness is about $350 \mathrm{~m}$ and whose cloud liquid water path increases with the depth of the cloud layer squared.

Because $\theta_{m}$ is so closely tied to the surface temperature $T_{s}$, to what extent might errors in the estimation of the latter affect the former? The $T_{s}$ estimated from the flight data averaged $292.2 \mathrm{~K}$, as compared with 290.9 and $291.9 \mathrm{~K}$ from TMI and ERA-40, respectively. ERA-40 SSTs are derived principally from infrared radiances measured by the AVHRR, which are not available under conditions of persistent cloud cover. Persistent cloud cover also biases the in situ measurements through sky effects (i.e., spurious component of the surface IR signal related to surface reflection of downwelling infrared radiation). In cloud situations, therefore, SSTs retrieved from microwave radiances from the TMI would seem the least subject to systematic errors. Assuming sky effects on the in situ data lead to a constant offset, this hypothesis is consistent with the better correlation between the TMI and flightestimated SSTs as compared with the reanalysis and flight estimated SSTs. The latter is -0.8 , and the former is commensurately strong but positive. Furthermore, if a poor representation of $\theta_{m}$ is an artifact of the poor representation of $\theta_{\text {SST }}$ we would also expect NNRA and ERA-40 estimates of $\theta_{m}$ to be well correlated, insofar as they share a common estimate of the SST. However, the correlation between $\theta_{1000}$ as given by NNRA and ERA-40 is only 0.29 for the entire month, which suggests that the source of the discrepancies among the data, for at least one of the reanalysis products, lies elsewhere.

These results suggest that the reanalysis products reasonably represent the thermodynamic and dynamic state of the lower troposphere above the PBL, but more poorly represent the structure and depth of the PBL itself. Because it has finer resolution, appears to be less noisy spatially, better represents the free-tropospheric thermal structure, and provides a more comprehensive description (i.e., the availability of products like boundary layer height, which despite mean biases correlates well with the observations), we believe that ERA-40 provides an improved representation of the northeast Pacific stratocumulus region as compared with NNRA.

\section{b. Divergence of horizontal winds}

The vertical motion $W$ on scales larger than a few kilometers is intrinsically bound up with the diabatic nature of the atmosphere. For this reason it is often

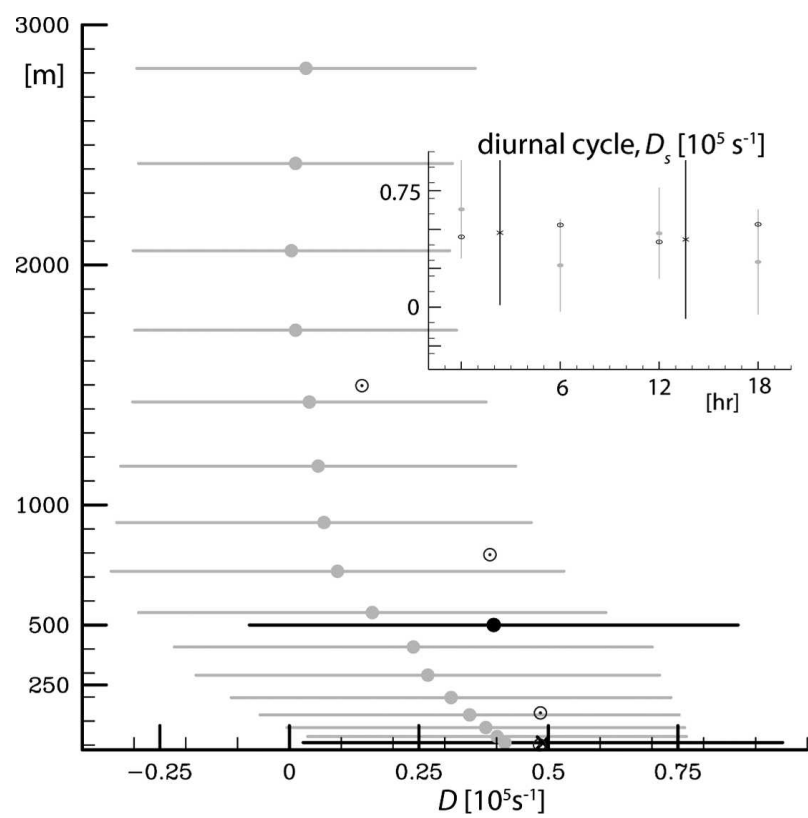

FIG. 6. Vertical profile of divergence averaged for all available July 2001 data from ERA-40 (gray solid dots), NNRA (open circles with center dot), flight data (black solid dot), and QuikSCAT (cross). The diurnal cycle showing $D_{s}$ at different analysis times and the ascending and descending QuikSCAT measurements are shown in the inset. Standard deviations from NNRA estimates are not shown, but are typically 2-5 times larger than those from ERA-40.

used as a proxy for dynamical regimes both in cloud parameterizations (Slingo 1980) and in analyses of cloud feedbacks (Bony et al. 2004), making it a crucial input to most models of small-scale processes. Unfortunately, the relatively small (as compared with the horizontal wind) magnitude of $W\left(z_{i}\right)$ makes it a challenging quantity to measure directly. During DYCOMS-II the circular flight patterns were optimized to provide estimates of the mean divergence within the PBL, $D_{m}$, using wind measurements from the aircraft as proposed by Lenschow et al. (1999), where, by continuity, $W\left(z_{i}\right)=-D_{m} z_{i}$. Lenschow et al. (2005, manuscript submitted to J. Atmos. Sci.) inferred $D_{m}$ for each of the entrainment flights, yielding the values of $D_{m}$ plotted in Fig. 3 as well as its flight-averaged value (plotted for convenience at $500 \mathrm{~m}$ ) in Fig. 6. As discussed by Lenschow et al. (2005, manuscript submitted to J. Atmos. Sci.), estimates of $D_{m}$ face a number of obstacles not anticipated by Lenschow et al. (1999), and as a result, the measurements should be treated more critically than the in situ estimates of more standard quantities (e.g., temperature and humidity).

In the absence of direct estimates of $D_{m}$, reanalysis data is often used (e.g., Wood and Bretheron 2004; Bretherton and Pincus 1995) to estimate $D$ and hence 
$W\left(z_{i}\right)$. Historically these estimates have been noisy, and not thought to be particularly reliable, which makes the correspondence between the aircraft-based estimates of $D_{m}$ and reanalysis-based estimates of $D$ surprisingly good. Also surprising (and at odds with assumptions in many simple modeling studies) is the extent to which significant divergence is trapped within the PBL, which raises the question as to whether specifying a fixed $W\left(z_{i}\right)$ or a fixed $D$ is most appropriate for modeling studies. In both reanalyses $D$ varies significantly with height, this being most pronounced for ERA-40, for which $D$ decreases with height over a depth commensurate with $z_{i}$. Tests with a higher-resolution (T511) version of the model, comparisons with the analyses, and averages taken over slightly larger areas showed that this tendency for $D$ to fall off so markedly within the PBL was not robust. The diurnal variation of $D_{s}$ is also shown by means of the inset to Fig. 6. Neither shows a clear and consistent pattern of diurnal variability over the DYCOMS-II study region. This result is in marked contrast to what has been inferred for the stratocumulus regions in the southeast Pacific, where it has been argued that the diurnal cycle of heating over the Andes is evident in the diurnal cycle of vertical velocity well offshore (Bretherton et al. 2004b; Garreaud and Muñoz 2005; Caldwell et al. 2005).

For the case of ERA-40 the fidelity of the reanalysis may simply reflect the accurate assimilation of winds from scatterometer data taken by the European Remote Sensing satellite, which was not available prior to 1991. For comparison, in Figs. 3 and 6 we also show estimates of $D_{s}$ taken from QuikSCAT. Again, the agreement is better than expected. $D_{s}$ as estimated from the QuikSCAT winds is nearly identical to that given by NNRA and only slightly larger than that produced by ERA-40. Overall, this level of agreement is consistent with the more extensive analysis of McNoldy et al. (2004) and contributes to the sense that surface divergence is well represented in the reanalyses, to the point of being useful for modeling studies.

\section{c. Cloud, and cloud-derived, fields}

In this section we evaluate the ability of routinely available data, with an emphasis on ISCCP, to reproduce the observed height $z_{i}$ of the cloud layer as well as its liquid water path $L$. Figure 3 suggests that PBL depths inferred from ISCCP cloud-top temperatures in combination with TMI SSTs agree well with what was measured in situ. Taking the average of the medians for the 12-h period centered at the flight time yields a mean ISCCP PBL depth of $751 \mathrm{~m}$, compared with a value of $755 \mathrm{~m}$ based on dropsonde and flight data. The RMS deviation is just under $200 \mathrm{~m}$, and the correlation is about 0.7. The differences are well within the uncertainty of the measurements-cloud-top temperature estimates from ISCCP alone have an uncertainty greater than $1 \mathrm{~K}$ (Wang et al. 1999).

Averaged over the study region for flight days, $L=$ $143,116,89$, and $72 \mathrm{~g} \mathrm{~m}^{-2}$ for the flight data, ISCCP, TMI, and AMSU products, respectively. Each is significantly larger than the $40 \mathrm{~g} \mathrm{~m}^{-2}$ given by ERA-40. The discrepancy among the microwave estimates (TMI versus AMSU) is consistent with previous studies (Grody et al. 2001). The tendency for $L$, as inferred from the flight data, to be larger than any of the satellite estimates may be partially attributed to diurnal biases. For ISCCP there is a clear morning-to-evening trend in both $L$ and cloud fraction. At 1500 UTC (0800 local time), cloud water has a July mean of $135 \mathrm{~g} \mathrm{~m}^{-2}$, which falls to $81 \mathrm{~g} \mathrm{~m}^{-2}$ by 2100 UTC. In terms of variability the story is less clear, the correlation between the cloud thicknesses inferred from flight data and TMI being 0.66 , rising to 0.77 for AMSU, and falling to 0.5 for ISCCP. But for each of these comparisons the significant diurnal cycle and the lack of temporal correspondence between the flight data and the other estimates impede our evaluation.

The tendency of the reanalysis to significantly underestimate $L$ is consistent with previous studies, and partially reflects its tendency to also underestimate cloud fraction in the region. Duynkerke and Teixeira (2001) compared ERA-15 (based on a 31-level T106 version of the model) with observations made on San Nicolas Island as part of the First ISCCP Regional Experiment. They show that diurnally averaged values of $L$ from ERA-40 were only about $10 \mathrm{~g} \mathrm{~m}^{-2}$ as compared with observed values nearer $70 \mathrm{~g} \mathrm{~m}^{-2}$. To the extent that the spatial structure of the July 1987 cloud field was similar to that during 2001 (e.g., Fig. 1), their study probably understates the discrepancies. This is because observed values of cloudiness over San Nicolas Island, which is on the outer edges of the Southern California Bight, tend to be consistently less than for the open ocean region between $28^{\circ}-34^{\circ} \mathrm{N}$ and $119^{\circ}-125^{\circ} \mathrm{W}$ over which their analysis of ERA-15 data was based. Duynkerke and Teixeira (2001) speculated that the poor representation of PBL clouds by ERA-15 was a result of the failure of the model to effectively mix moisture through a sufficiently deep layer, perhaps due in part to the model's coarse vertical resolution. Because the estimate of the PBL depth is available in ERA-40, here we can say with some certainty that the most significant obstacle to a realistic representation of PBL clouds is the overly shallow PBL. Relative to ERA-15, ERA-40's vertical resolution is greatly enhanced, so it is difficult 
TABLE 3. Reanalysis and forecast averages for July 2001. Here $\theta$ is averaged on model levels, thus $\theta_{850}$ is actually valid on model levels 49 and 32 for IFS and GFS, respectively, which correspond to average pressures of 860 and $846 \mathrm{hPa}$. Likewise, $\theta_{m}$ is averaged on model levels 56 and 40 for IFS and GFS, respectively. On these levels, both models average a mean pressure of $993 \mathrm{hPa}$.

\begin{tabular}{lcrrrrrr}
\hline \hline & & \multicolumn{2}{c}{ IFS } & & \multicolumn{2}{c}{ GFS } \\
\cline { 3 - 4 } \cline { 6 - 7 } \multicolumn{1}{c}{ Field } & ERA-40 & $0-24$ & $24-48$ & NNRA & $00-24$ & $24-48$ \\
\hline$\theta_{850}(\mathrm{~K})$ & 306.9 & 306.0 & 306.0 & 308.1 & 307.6 & 307.0 \\
$q_{850}\left(\mathrm{~g} \mathrm{~kg}^{-1}\right)$ & 3.8 & 3.9 & 3.5 & 4.1 & 3.7 & 3.5 \\
$\theta_{m}(\mathrm{~K})$ & 288.2 & 288.5 & 288.3 & 288.0 & 291.6 & 292.4 \\
$q_{m}\left(\mathrm{~g} \mathrm{~kg}^{-1}\right)$ & 9.6 & 9.7 & 9.7 & 9.8 & 9.1 & 9.2 \\
$u_{m}\left(\mathrm{~m} \mathrm{~s}^{-1}\right)$ & 2.1 & 3.3 & 3.5 & 3.8 & 3.5 & 3.7 \\
$v_{m}\left(\mathrm{~m} \mathrm{~s}^{-1}\right)$ & -6.1 & -6.3 & -6.4 & -5.7 & -6.2 & -5.8 \\
$z_{i}(\mathrm{~m})$ & 460 & 480 & 480 & - & 510 & 480 \\
\hline
\end{tabular}

to argue that this is simply a problem of insufficient vertical resolution.

In summary, boundary layer depths inferred from ISCCP cloud-top temperatures and TMI SSTs match the observed boundary layer depths remarkably well. Estimates of $L$ from ISCCP optical depths also represent the observed cloud liquid water path as well as estimates derived from microwave-based retrievals. NNRA does not provide estimates of either $z_{i}$ or $L$. Both quantities are underestimated in ERA-40.

\section{d. Inferences from forecast models}

Here we evaluate the ECMWF IFS and NCEP GFS using the DYCOMS-II data. Doing so gives further insight into the ability of the models underlying the reanalyses to represent the structure of the lower troposphere in the study region. This is particularly true for ERA-40, which was produced using the same version of the IFS as was being used to generate forecasts in July of 2001 (Uppala et al. 2005). Because ERA-40 incorporated the dropsondes from the field program, such a comparison also allows us to evaluate how the IFS behaved in the absence of the dropsonde data. In the case of NCEP, an analysis of the GFS data allows us to examine a product on spatial scales more commensurate with the study region. This analysis also provides an opportunity to investigate NCEP's representation of the PBL depth and cloud cover, neither of which were available as reanalysis products.

Table 3 lists the value of state variables from the IFS and GFS forecasts averaged between 0000 UTC and hour 24, and between hour 24 and hour 48, for every day of July 2001, as well as averages for all of July from ERA-40 and NNRA. For identical initial data and stationary statistics, a perfect model should yield identical representations of the mean state among these three representations, each corresponding to the observed
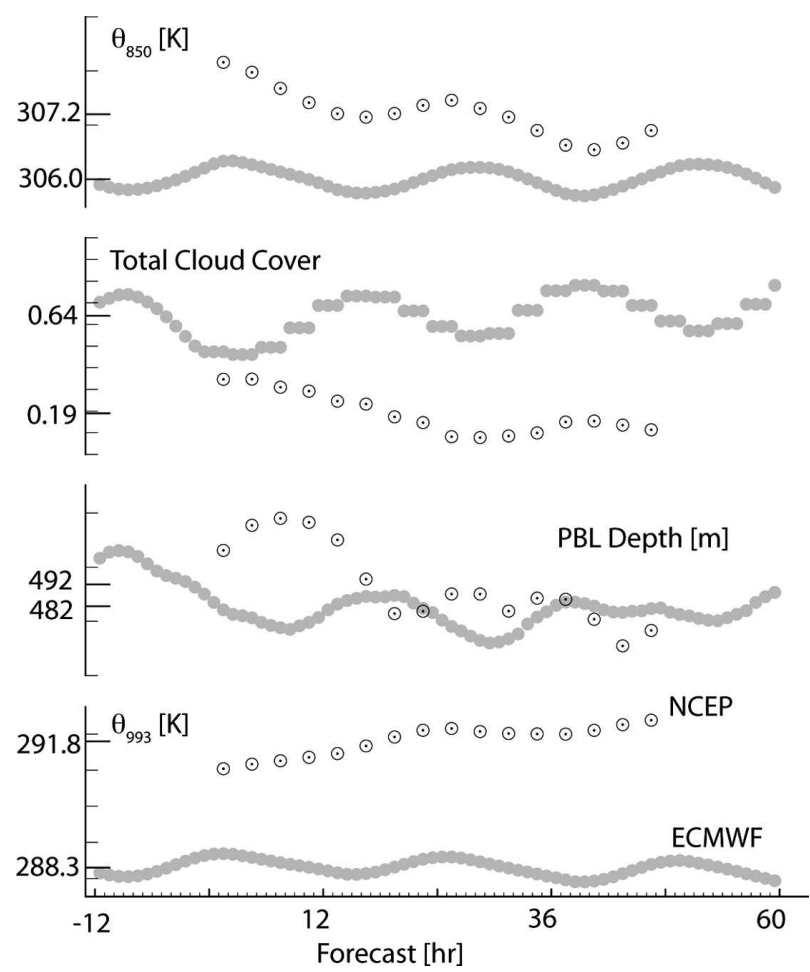

FIG. 7. July average at each forecast hour for selected fields from ECWMF (gray circles) and NCEP (open circle with center dot): (top to bottom) $\theta_{850}$, total cloud cover, PBL depth, and $\theta_{993}$.

state. From the table it is apparent that the IFS is quite consistent with its reanalysis product (ERA-40), with the only significant trend being an increase in the zonal winds later in the forecasts. From this we conclude that the fidelity of the ERA-40 time-mean products is unlikely to be a result of the incorporation of special data. The same conclusion cannot be drawn for NNRA, as within the PBL the GFS develops a large (3 K) warm and modest dry bias almost from the start. The warm bias increases through the forecast period. A similar bias is evident in comparisons of the structure of the stratocumulus-topped boundary layer as represented by the GFS and as observed during the East Pacific Investigation of Climate (EPIC; Bretherton et al. 2004b, their Fig. 10), suggesting that this is not a regional effect. The GFS and IFS predict PBL depths that look more similar to each other than to the data.

July averages of $\theta$ near $850 \mathrm{hPa}$, total cloud cover, PBL depth, and $\theta$ near $993 \mathrm{hPa}$ are plotted versus forecast hour in Fig. 7. The different start times reflect the initialization at 1200 UTC on the previous day for the 72-h IFS forecasts as compared with the 0000 UTC initialization for the 48-h GFS forecasts. In addition to illustrating the mean state biases noted above (e.g., $\theta_{993}$ from the GFS), Fig. 7 indicates that the GFS has larger temporal trends and a markedly weaker diurnal cycle. 


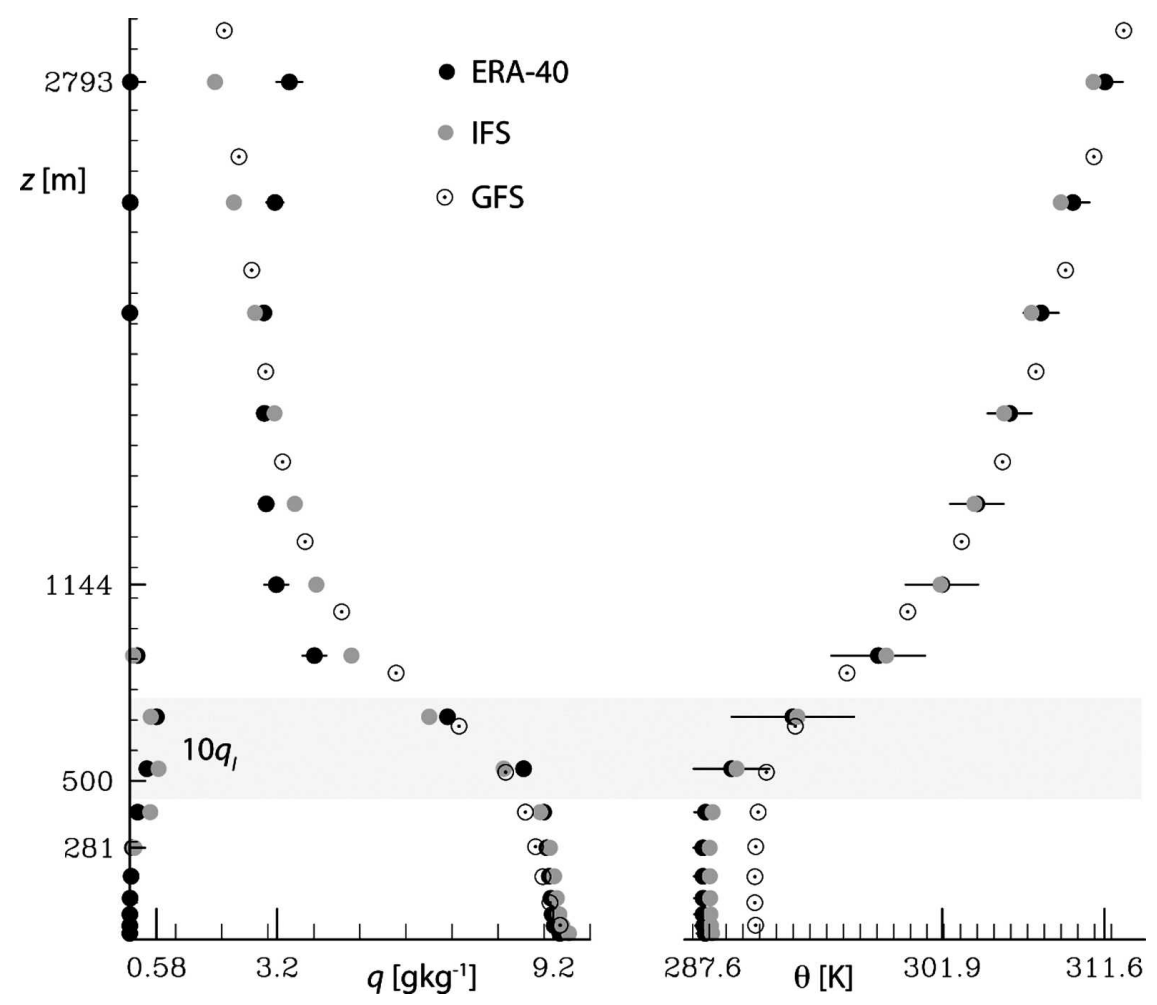

FIG. 8. Mean profile for 10-20 Jul 2001, for ERA-40, GFS, and IFS forecasts, averaged over the first $24 \mathrm{~h}$ of the forecast. For guidance the position of the observed cloud layer is indicated by the shading. Profiles for liquid water are multiplied by 10 and do not include GFS.

Moreover, despite the shortcomings of the IFS, its representation of PBL clouds is clearly superior to that of the GFS. These results provide further evidence that, overall, the IFS-based ERA-40 represents the structure of the lower troposphere near $30^{\circ} \mathrm{N}, 120^{\circ} \mathrm{W}$ during July 2001 better than the earlier-generation GFS-based NCEP product.

Figure 8 illustrates the vertical structure of $\theta$ and $q$ from ERA-40, IFS, and GFS for the period 10-20 July. In addition to more pointedly illustrating the warm bias of the GFS, and a slight tendency of the GFS PBL to be less well mixed in terms of specific humidity, these profiles show that while each of the products qualitatively capture the gross structure of a shallow marine layer, the transition between the PBL and the free troposphere takes place over too deep a layer. This transition layer, which is several hundreds of meters in depth in the models, is much sharper in the data: temperatures increase $10 \mathrm{~K}$ or more, while ozone, chemical constituents, and water vapor often fall to background values, in tens of meters or less (Stevens et al. 2003a). Although some smearing of the mean interface can be expected because of spatial and temporal variability in the PBL depth, during the 10 days over which data was averaged to construct Fig. 8 the ERA-40 PBL depth averaged $600 \mathrm{~m}$ with a standard deviation of $88 \mathrm{~m}$. Thus, the thickness of the transition layer is unlikely to be a result of great temporal variability in the depth of a PBL topped at any given time by a much sharper interface, but rather due to an inability of the model physics and numerics to maintain such a sharp interface. Telling in this respect is the structure of the cloud field. It is placed at about the right altitude by both the reanalysis and the forecast systems, but because the models produce a much shallower mixed layer, this corresponds to a level more centered in the model inversion, rather than at the top of the STBL as is the case for the data. Moreover, the cloud field has significantly less liquid water. At any given grid point the liquid water specific humidity never exceeds $0.1 \mathrm{~g} \mathrm{~kg}^{-1}$ in the 10-day IFS record, which is more than an order of magnitude less than expected. As a result the structure of the mean profiles is more reminiscent of shallow cumuliform convection than it is of stratocumulus convection.

\section{A routine July?}

The above analysis gives an idea of the large-scale variability and STBL structure for one particular July. It also gives an indication of the skill with which differ- 

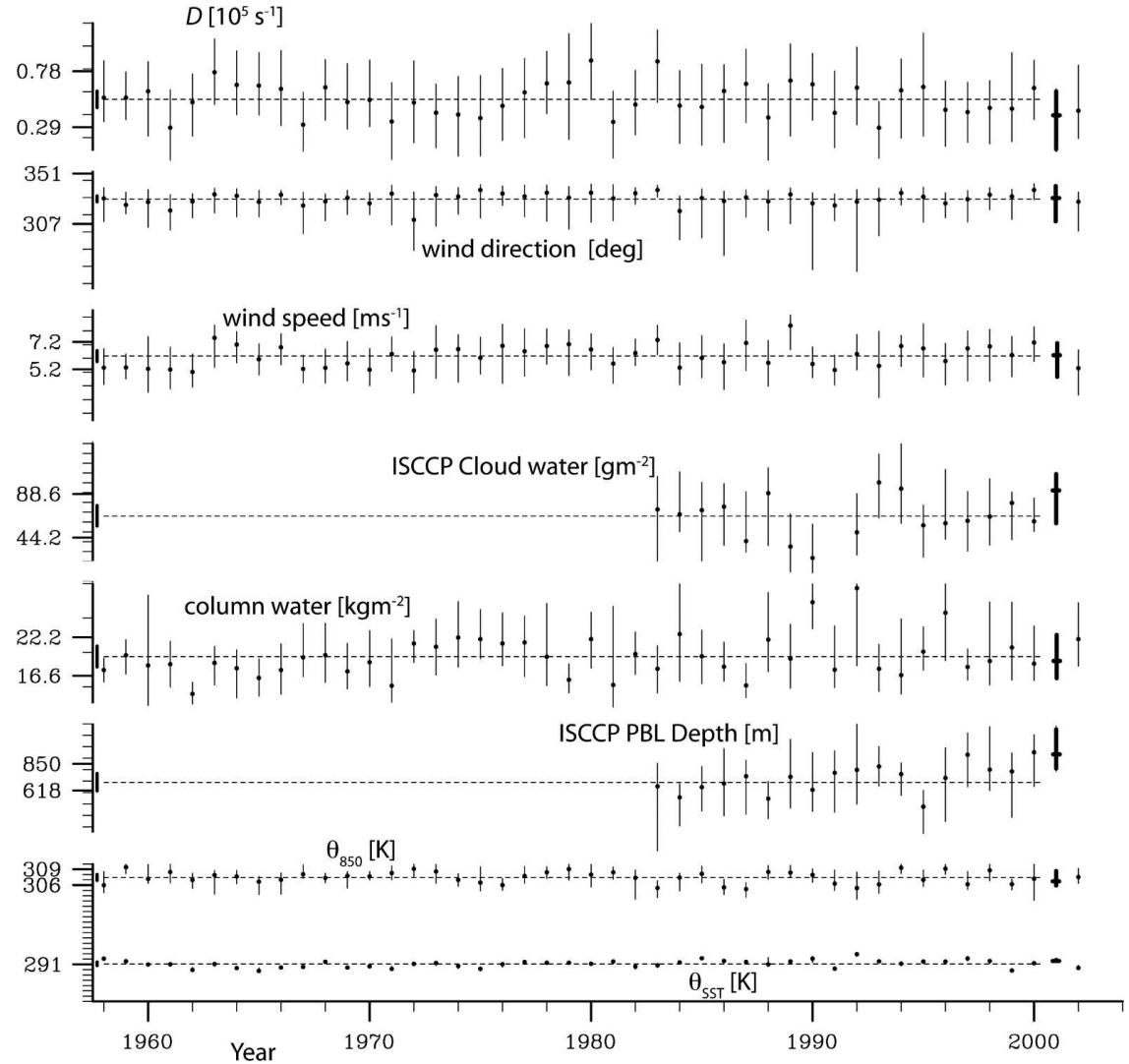

FIG. 9. Summary of year-to-year variability in July following the format in Fig. 3. Data for 2001 are in boldface. The climatological mean is used as a reference for the dashed base lines. The $y$-axis labels mark the one standard deviation spread for an average month, while the thickened vertical bar just inside the $y$ axis measures the $2 \sigma$ value of interannual variability.

ent aspects of the lower troposphere are accurately represented by more routine data spanning a longer time period. If we assume that routine data that well represented the state of the lower troposphere in July 2001 will also be skillful in other years, it becomes useful to ask how representative our data is of a typical July, as well as to explore covariability across a variety of different fields. For this purpose we focus on two products: ERA-40 and ISCCP. For the former we examine the winds (including their divergence), total water path, SSTs, and free-tropospheric thermal structure, while for the latter we focus on the PBL depth (derived using the ISCCP cloud-top temperatures and the ERA-40 SSTs) and cloud liquid water path. In most cases, these data were shown by our previous analysis to correspond well with the available data (the exceptions being the SSTs from ERA-40 and to a lesser extent the zonal component of the PBL wind). Both records are advantageous because they span many years. The ERA-40 record includes more than 40 Julys while ISCCP began processing data from July 1983. This underlines a point first made in the introduction: even the ISCCP record now has as long a time series as the OWS record upon which much past empiricism has been based.

Figure 9 illustrates the year-to-year and day-to-day variability for all of the available data from ISCCP and ERA-40. The format was chosen to be similar to that used for Fig. 3, except here we only give a single estimate for each field, and the variability now represents monthly variations rather than spatial variability or sampling uncertainty. Variability within a month is measured by the whiskers that span the distance between the first and third quartiles. Interannual variability is shown by a $2 \sigma$ bar centered on the long-term mean and plotted just inside the vertical axis for each field. Figure 9 illustrates a number of points: (i) July 2001 near $30^{\circ} \mathrm{N}, 120^{\circ} \mathrm{W}$ was unusual, although not anomalous, in terms of its degree of cloudiness, the depth of the PBL, the weakness of the large-scale divergence, and the relative weakness in the lowertropospheric stability; (ii) synoptic variability is on the same order as interannual variability; (iii) the layer above the PBL tends to evince more variability than the PBL. The latter point is most evident in comparisons of 


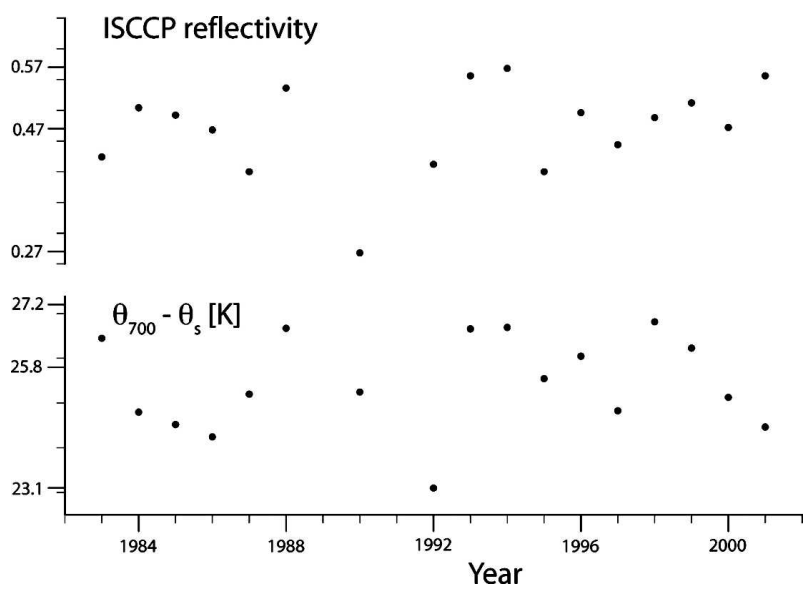

FIG. 10. (top) ISCCP daytime cloud reflectivity and (bottom) lower-tropospheric stability. Julys for which the ISCCP record has fewer than 10 days of data over our study region are excluded from the record.

year-to-year variations in SSTs with interannual variations in $\theta_{850}$. This larger variability appears to be true for synoptic through decadal time scales, with $\theta_{850}$ evincing sufficiently pronounced decadal variability to warrant further study.

If we examine just those years for which we have ISCCP data available, we note that the increased depth in the PBL during 2001 is part of a longer-term trend in the data, which is almost exclusively due to changes in cloud-top temperatures with time. A regression against time yields a deepening rate of about $150 \mathrm{~m} \mathrm{decade}^{-1}$, which is significant at the $99.5 \%$ level, although such analysis does not preclude the possibility that it is an artifact in the data. The apparent deepening rate is also evident, albeit weaker and less significant, if the broader region between $20^{\circ}$ and $30^{\circ} \mathrm{N}$ and $120^{\circ}$ and $130^{\circ} \mathrm{W}$ is examined.

Because $\Delta \theta$ is being used as a parameterization of cloudiness in some climate models, it is interesting to revisit the question of interannual correlations between $\Delta \theta$ and cloudiness using a combination of the ISCCP data and the reanalysis. Toward this end the values of $\Delta \theta$ and cloud reflectance are plotted in Fig. 10 for those Julys in our ISCCP record. These variables, which both evince a slight upward trend in time, do not appear to be otherwise well correlated. The trend is also evident over the broader northeast Pacific stratocumulus region and is consistent with a general tendency toward increasing low-cloud amounts in the surface observer record (Norris 1999), and counter to known biases associated with changing satellite view angle effects (Campbell 2004). Nonetheless it is sufficiently small, and the platforms from which the ISCCP data are derived are sufficiently inhomogeneous, to warrant its treatment with some skepticism. In terms of the year-to-year variance in cloud reflectivity, only about $30 \%$ of it can be explained by variations in the $\Delta \theta$, a correlation which, given the length of the record, is not especially significant. This correlation shows some sensitivity to how many ISCCP observations are required (some years have more missing data than others) before a monthly mean is included in the record, tending to improve if the threshold number of observations necessary to include a month's data in the record is increased, or if the analysis area is expanded. However, no simple change to the analysis procedure is capable of raising the correlations to values reported by Klein and Hartmann (1993), who found that nearly two-thirds of the variance in cloud amount could be explained by variations in stability at OWS N.

Although we frame the comparison differently than Klein and Hartmann (1993), using cloud reflectivity rather than cloud amount, we believe the discrepancy is not simply a question of definitions. In Fig. 11 we plot the long-term mean ISCCP daytime cloud reflectivities overlaid with contours of $\Delta \theta$ on the left and the interannual correlation coefficient between the two on the right. For reference, OWS N, whose data formed the basis of the Klein and Hartmann (1993) analysis, was located at $30^{\circ} \mathrm{N}, 140^{\circ} \mathrm{W}$, near the edge of the climatological maximum in low-cloud amount. This figure shows that interannual correlations between stability and cloud amount are best in regions where gradients in cloud amount are aligned with gradients in stability. Conspicuously, OWS $\mathrm{N}$ was in just such a location, and at this location we are able to reproduce the tight correspondence between cloud amount (reflectivity) and lower-tropospheric stability. In contrast, over the bulk of the stratocumulus region changes in $\Delta \theta$ of $6 \mathrm{~K}$ can be found across regions where the cloud reflectivity is constant. Likewise, cloud reflectivity changes markedly along stability contours. If anything, this analysis shows that the lack of correlation between stability and cloud amount over the DYCOMS-II area is not likely due to slight differences in how we form the stabilities, or how we define the cloud presence, but rather that it is more representative of the broader region of stratocumulus than are variations in transitional cloudiness as were measured at OWS N.

\section{Discussion}

To aid future studies, Fig. 12 summarizes the state of the lower troposphere for July 2001 near $30^{\circ} \mathrm{N}, 120^{\circ} \mathrm{W}$. The mean profile has been constructed so as to reproduce both the observed PBL structure and the microwave estimates of the total water path. Doing so requires a significantly drier free troposphere just above 

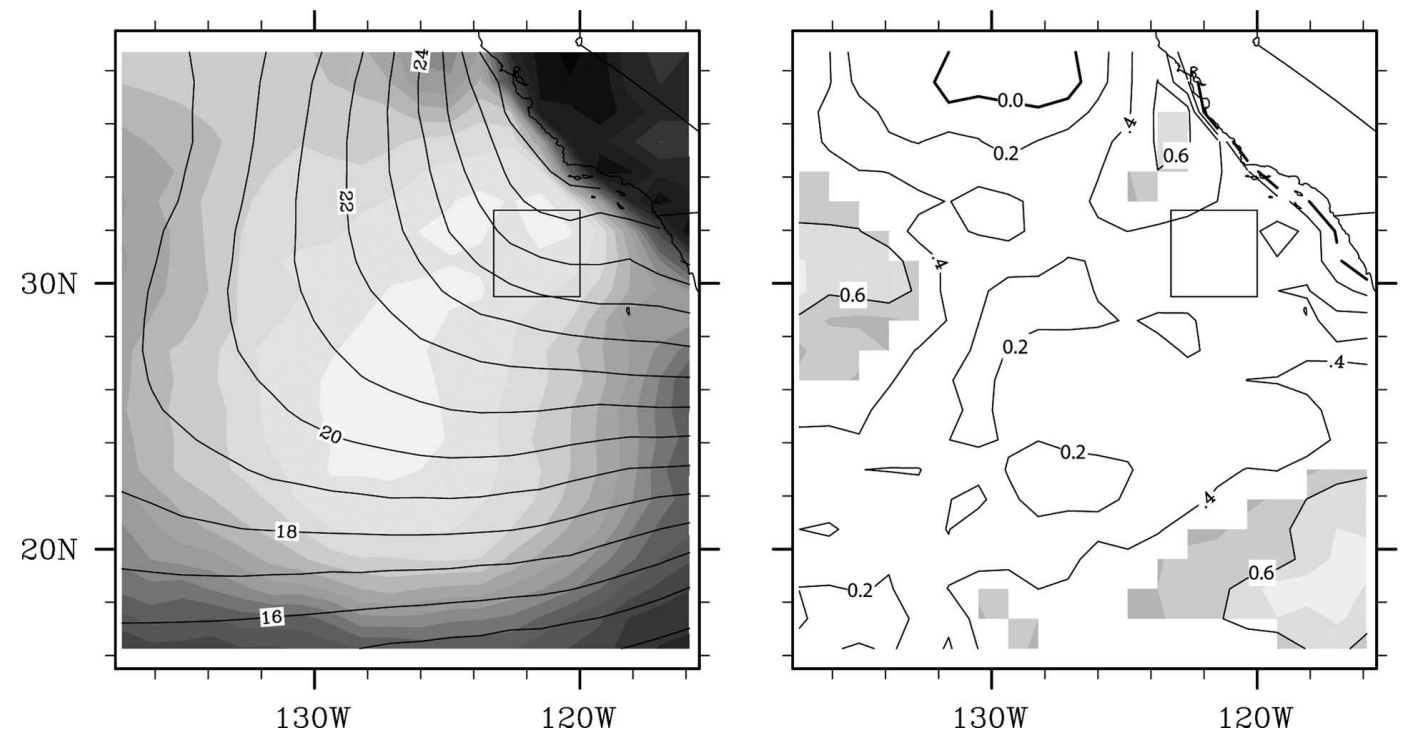

FIG. 11. (left) Lower-tropospheric stability (contours) and ISCCP daytime cloud reflectivity (shaded, using color bar in Fig. 1) and (right) interannual correlation coefficient between these two fields. Shading on right denotes correlations significant at $95 \%$ and $99 \%$ levels.

the STBL than is produced by either the forecast models or the reanalyses. However, matching the total water path in this way leads to a differentiation between the STBL and the air just above, leading to better agreement with the flight data. The temperature profile in the layer just above the PBL is crafted to increase with height following the analysis for the first research flight (Stevens et al. 2003a), whose value of large-scale divergence was close to the monthly mean and implies large-scale subsidence rates of $-3 \mathrm{~mm} \mathrm{~s}^{-1}$ at the cloud top. The cloud base in the diagram is taken to be the LCL of the mean sounding, and the cloud top is taken to be the mean of the 10 flights. This produces a cloud layer of $320 \mathrm{~m}$. Given the DYCOMS-II mean liquid water lapse rate of $1.5 \mathrm{~g} \mathrm{~kg}^{-1} \mathrm{~km}^{-1}$, this implies a cloud liquid water path of $84 \mathrm{~g} \mathrm{~m}^{-2}$, consistent with monthly averages derived from ISCCP (e.g., Fig. 9). The cloud top is expected to be a sharp interface locally, but with height varying spatially on scales of one to tens of kilometers. This thickens the mean interface on the scale of the study region that we model by assuming the sharp interface to be normally distributed about its mean height with a standard deviation $(30 \mathrm{~m})$ given by the spread of the lidar data in Fig. 3. The sea surface temperature and specific humidity are also indicated on the diagram, which given a mean wind speed of 7.3 $\mathrm{m} \mathrm{s}^{-1}$ implies surface sensible and latent heat fluxes of 4.7 and $65 \mathrm{~W} \mathrm{~m}^{-2}$, respectively.

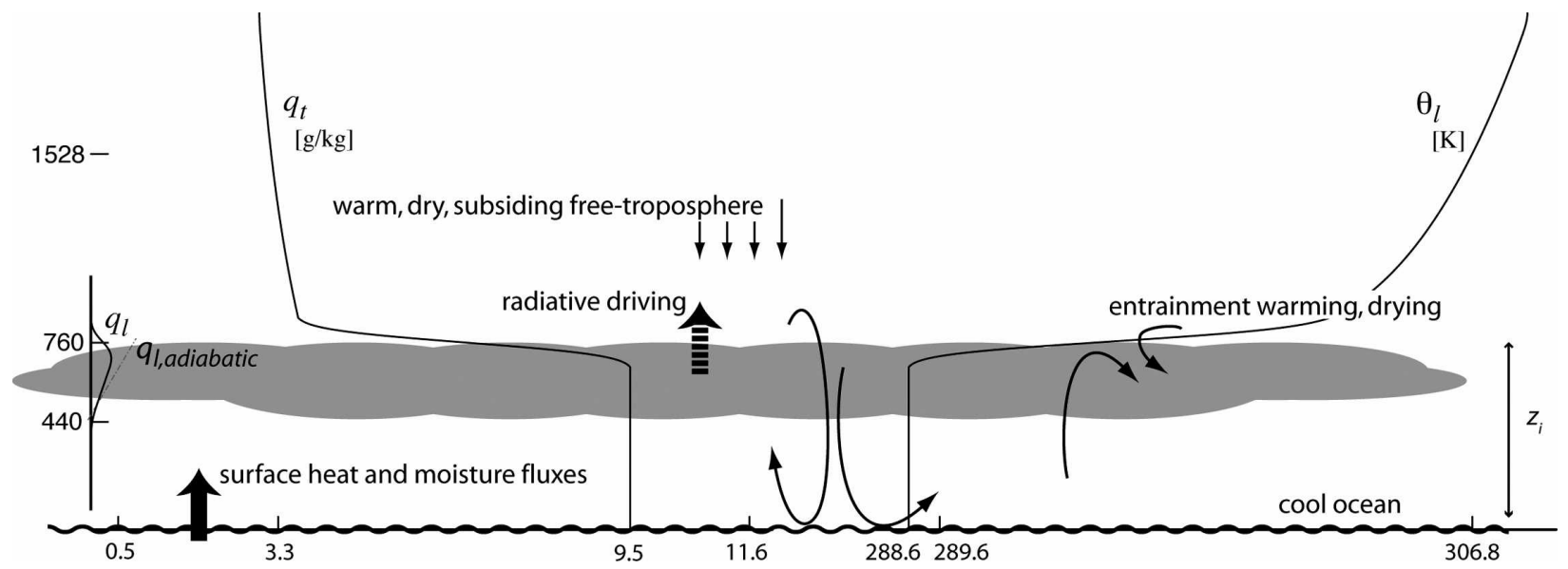

FIG. 12. Sketch of mean thermodynamics structure of the lower troposphere for July 2001 near $30^{\circ} \mathrm{N}, 120^{\circ} \mathrm{W}$. The potential temperature, specific humidity, and height at $850 \mathrm{hPa}$ are indicated, as are values within the STBL and at the sea surface. 
To complete this picture we draw on previous analyses of the DYCOMS-II data. Radiative driving from the flux divergence of longwave radiation across cloud top is about $70 \mathrm{~W} \mathrm{~m}^{-2}$, of which roughly $20 \mathrm{~W} \mathrm{~m}^{-2}$ is compensated by convergence, or warming, across the cloud base (Stevens et al. 2003b; vanZanten and Stevens 2005). Turbulence intensities can be measured by the rate of dissipation of turbulence kinetic energy, which was estimated to be between 5 and $10 \mathrm{~cm}^{2} \mathrm{~s}^{-3}$, corresponding to RMS fluctuations in the vertical velocity of about $0.7 \mathrm{~m} \mathrm{~s}^{-1}$ at the cloud base (Stevens et al. 2005a; Lothon et al. 2005). The above are all nocturnal values. During the daytime, when the longwave radiative driving of the layer is substantially offset by the absorption of shortwave radiation, one would expect less turbulence, a less well-mixed structure, and a commensurately thinner cloud.

An aspect of the observed STBL structure that we have not discussed, and that is not represented in Fig. 12 , is precipitation. Recent studies have shown that sedimentation of cloud droplets can have a nontrivial influence on cloud dynamics (Ackerman et al. 2004). Similarly, vanZanten et al. (2005) found that on roughly a third of the flights, precipitation rates at the cloud base averaged about $1 \mathrm{~mm}$ day $^{-1}$. Precipitation fluxes of this order can be expected to contribute substantially to the energetics of the cloud layer and should be included in any basic description of stratocumulus. However, interpreting the microphysical information that exists in routine radiance measurements in light of the DYCOMS-II data goes beyond the scope of the present study, in part because such retrievals tend to unreliably predict drizzle, especially in regions of broken clouds where drizzle is thought to prevail (Stevens et al. 2005b). CloudSat (Stephens et al. 2002) has the potential to change this, but it remains to be seen how effectively it can probe the structure of such shallow cloud layers.

A comparison of the sounding in Fig. 12 with that in Fig. 8 emphasizes the chief shortcoming of the forecast and reanalysis systems: their inability to produce a sufficiently deep, and well-mixed, PBL, and hence a marked underprediction of cloud amount. Both the GFS and IFS share the $K$-profile approach outlined by Troen and Mahrt (1986), which does not recognize moist processes. As a result, a well-mixed STBL, which has $\theta$ increasing at, or near, the moist adiabatic lapse rate in the cloud layer, will appear to be a stable layer to a dry parcel. This impacts both the diagnostic of the PBL depth and the mixing rates, as the latter are typically scaled by the rate at which turbulence kinetic energy is generated at the surface (i.e., cloud and radiative driving of turbulence are not incorporated). Conse- quently, PBL depths will tend to be diagnosed near the cloud base level, and mixing within the PBL will be relatively weak, which is consistent with the structure of the PBL as represented by both the GFS and IFS. A further weakness of most $K$-profile models is that the entrainment rate (i.e., the rate at which freetropospheric air is mixed into the PBL) is not set explicitly. Instead, this mixing rate is usually determined by the level where the PBL top is diagnosed relative to model levels. This can lead to too much mixing between the PBL and the overlying free atmosphere, all the while maintaining a shallow PBL. This problem may explain the poor performance of the GFS (i.e., rapid warming of the PBL but without associated deepening).

It has long been appreciated that, from the point of view of the STBL, simply modifying the diagnostic for the PBL depth to better account for moist processes, for instance through the use of thermodynamic variables that are invariant for moist-adiabatic processes, can lead to significant improvements in model performance. Further improvements can be expected by accounting for cloud and radiative processes in the energetics, and by controlling the entrainment rates (e.g., Lock 2004; Bretherton et al. 2004a). Recent work along these lines at ECMWF is also yielding satisfying results. Specifically, a hybrid $K$-diffusion [i.e., Troen and Mahrt (1986) class scheme] and mass flux parameterization has been implemented. Its main ingredients include the following: (i) the use of moist-conserved variables, (ii) a combined mass flux-K-diffusion solver, (iii) a treatment of cloud variability, and (iv) a treatment of the transition between stratocumulus and shallow convection with typically high and low cloud cover, respectively. The effects of this upgrade were evaluated in a full resolution T511 reanalysis of the period from 7 to 27 July 2001. Cloud cover and cloud liquid water path, which had values of $50 \%$ and $25 \mathrm{~g} \mathrm{~m}^{-2}$, respectively, in the T511 analysis with the old PBL formulation, improved to $85 \%$ and $72 \mathrm{~g} \mathrm{~m}^{-2}$, respectively, with the revised model. Similar improvements were evident in the other marine STBL regions. The height of the mixing also increased, from near 400 to about $600 \mathrm{~m}$, mostly as a result of the first and fourth changes above. The details of the changes to the model, and a more thorough evaluation of its behavior, will appear in a forthcoming manuscript.

\section{Conclusions}

Aircraft observations made during the DYCOMS-II field study are used to evaluate routine (satellite and reanalysis) data describing the stratocumulus-topped boundary layer near $30^{\circ} \mathrm{N}, 120^{\circ} \mathrm{W}$ during July 2001 . 
This exercise helps identify the most useful sources of routine data for the purpose of evaluating the STBL in the northeast Pacific and its variability through the course of the satellite record. Some of our findings worth highlighting here include the following:

- Cloud-top temperatures from ISCCP combined with microwave estimates of SSTs, a mean DYCOMS-II temperature lapse rate of $8 \mathrm{~K} \mathrm{~km}^{-1}$, and a fixed airsea temperature difference of $1 \mathrm{~K}$, reproduces the depth of the STBL and its variability on synoptic time scales. ISCCP optical depths also serve as a useful proxy for the cloud liquid water path in the stratocumulus region of the northeast Pacific.

- ERA-40 and the ECMWF IFS admirably reproduce the structure of the thermodynamics environment above the PBL as well as the large-scale divergence impressed upon it. NNRA/GFS products represent the moisture and divergence structure with a fidelity similar to ECMWF products, but at much coarser resolution. They also suffer from a slight $(1.5 \mathrm{~K})$ warm bias near $850 \mathrm{hPa}$ during the period of our analysis.

- Both NNRA/GFS and ECMWF products are more deficient in their representation of the STBL itself, with such deficiencies being most pronounced in the NCEP GFS forecast product. In every representation the boundary layer is too shallow, tending to correspond more closely to cloud-base height rather than cloud top, cloud liquid water paths still tend to be a factor of 2-4 less than observed, and boundary layer temperatures are found to correlate poorly with the observations. In ERA-40 there is also evidence of zonal winds near the surface being too weak through the analysis period. GFS forecasts exhibit a striking $(3 \mathrm{~K})$ warm bias within the STBL, and show much greater drift with forecast hour, and less realistic diurnal variability than is evident in the IFS.

Based on this analysis we believe that ERA-40 is most usefully combined with ISCCP data to explore the variability in the structure of the lower troposphere in the stratocumulus region of the northeast Pacific over longer time periods. So doing suggests that the interannual correlation between lower-tropospheric stability and cloud amount at OWS $\mathrm{N}$ does not hold broadly across the region. This highlights the difficulty of making climate observations from fixed spatial locations, even over the open ocean. Other interesting findings include the identification of an apparent upward trend in cloud amount over the heart of the stratocumulus region of the northeast Pacific, as well as a tendency toward deeper boundary layers within the DYCOMS-II study region. Both issues merit further study.
Acknowledgments. ECMWF ERA-40 data used in this study have been obtained from a variety of locations, including the ECMWF data server, and from the data systems section at NCAR. NNRA data were provided by the NOAA-CIRES Climate Diagnostics Center, Boulder, Colorado (from their Web site online at http://www.cdc.noaa.gov). The ISCCP DX data were obtained from the ISCCP data archives maintained by the NASA DAAC. Dave Stepaniak is thanked for his help with the ERA-40 reanalyses, discussions with Bill Rossow helped facilitate the ISCCP analysis, and HuaLu Pan helped provide the GFS data. The QuikSCAT Level 3 Ocean Wind Vector data are obtained from the Physical Oceanography Distributed Active Archive Center (P0.DAAC) at NASA JPL in Pasadena, California (see online at http://podaac.jpl.nasa.gov). TMI data are produced by Remote Sensing Systems and sponsored by the NASA Earth Science REASoN DISCOVER Project. (Data are available online at http:// www.remss.com.) GOES-10 data were obtained from the Space Science and Engineering Data Center at the University of Wisconsin. This work was supported by NASA through Fellowship NGT530499 and Grant NAG512559. Comments by B. Albrecht, C. Bretherton, and S. Klein on an early draft of this manuscript greatly improved its presentation.

\section{APPENDIX A}

\section{Satellite Data}

Near-surface $(10 \mathrm{~m})$ winds are obtained from QuikSCAT through the National Aeronautics and Space Administration (NASA) Jet Propulsion Laboratory (JPL) level-3 daily wind vectors product with a horizontal grid spacing of $0.25^{\circ}$. Typically, the ascending and descending satellite passes correspond to northeast Pacific crossing times near 1400 and 0200 UTC, respectively. The exact crossing time and the degree of coverage varies with a 4-day cycle, with periods of bursts of closely spaced samples separated by longer temporal gaps. Over the study region, the largest temporal gap between subsequent samples is about $36 \mathrm{~h}$. Schlax et al. (2001) estimate mean sampling errors for QuikSCAT to be about $0.3 \mathrm{~m} \mathrm{~s}^{-1}$ for a 2-day average over a $1^{\circ}$ grid, this being perhaps an order of magnitude better than wind estimates from the first and second ERS satellites, which were incorporated into the ERA-40 form the early 1990s. QuikSCAT winds are not assimilated by either the NNRA or ERA-40 (McNoldy et al. 2004).

The TMI provides measurements of sea surface temperature, cloud liquid water path, wind speed, and total water path (its rain-rate product is not used in this 
study) on a global region extending from $40^{\circ} \mathrm{S}$ to $40^{\circ} \mathrm{N}$ with a spatial resolution of $0.25^{\circ} \times 0.25^{\circ}$. Because of the semiequatorial, nonsunsynchronous satellite orbit, the ascending and descending passes sample any given earth location at changing local times. Compared with the AVHRR retrievals of SSTs from infrared radiances, the technology of microwave imaging implemented on the TMI offers the advantage of providing all-weather measurements with a comparable accuracy to and better coverage than infrared retrievals, with downside of a lower spatial resolution $(\sim 47 \mathrm{~km})$. In situ studies have shown that while the AVHRR Pathfinder SST has a $0.02-\mathrm{K}$ bias and $0.53-\mathrm{K}$ standard deviation when compared with buoy data (Kilpatrick et al. 2001), the TMI SSTs have a $-0.08-\mathrm{K}$ bias and a $0.53-\mathrm{K}$ standard deviation (Gentemann et al. 2004). Quantitative investigation of the SST availabilities of infrared and microwave measurements show that the annual mean availabilities of AVHRR and TMI are $48 \%$ and $78 \%$, respectively (Guan and Kawamura 2003). These differences were much more pronounced in the cloud fields sampled during DYCOMS-II (i.e., about $5 \%$ for the AVHRR compared with nearly effectively full coverage for TMI).

An additional source of total column water vapor and cloud liquid water data is AMSU-A from the NOAA-15 polar-orbiting satellite. The satellite makes approximate passes over our study region around 1507 and 0325 UTC (0659 and 1917 local time, respectively). The raw data include 15-channel passive microwave brightness temperatures, which have been processed through a statistical retrieval model intended for climate study and available at $1^{\circ} \times 1^{\circ}$ spatial resolution (Goldberg 1999). Grody et al. (2001) compared AMSU column water variables from the same satellite (although using a physical model retrieval, rather than a statistical one) with radiosonde data as well as Special Sensor Microwave Imager and TMI satellite data. The RMS retrieval errors relative to radiosonde data were found to be less than $3 \mathrm{~kg} \mathrm{~m}^{-2}$ for total column water vapor with systematic error less than $1 \mathrm{~kg} \mathrm{~m}^{-2}$ (within the range of $5-60 \mathrm{~kg} \mathrm{~m}^{-2}$ ). These accuracies are estimated for nonprecipitating conditions with about 50$\mathrm{km}$ horizontal resolution. The cloud liquid water accuracy is not as good, but the data closely follow groundbased time series and the TMI values and are within the same range.

\section{APPENDIX B}

\section{Reanalysis and Forecast Products}

ERA-40 is derived from a three-dimensional variational technique applied using the ECMWF IFS run with a T159 truncation and 60 vertical levels. Twelve of the levels are in the lower troposphere (at pressures greater than $850 \mathrm{hPa}$ ). Most of our analysis is based on fields taken from the full resolution model and made available in the "grid in binary" (GRIB) format. This often entails working in terms of spherical harmonics. In such cases the sphere pack routines (Adams and Swarztruabuer 1997) are used to interpolate to a Gaussian grid, whose grid spacing over the target area is about $1.1^{\circ}$ in both latitude and longitude. Beginning in January 2001 the ERA-40 SSTs were taken from the optimal interpolation SST scheme (version 2.1) described by Reynolds et al. (2002). This method combines in situ and satellite data (from the AVHRR) on a $1^{\circ}$ grid to make weekly SST estimates, which are then interpolated to provide daily estimates (Fiorino 2004). Cloud contamination in the AVHRR data (which would have been frequent in the DYCOMS study region) is expected to contribute a negative bias, although the primary purpose of the in situ data is to help correct such biases (Reynolds et al. 2002).

By chance, both ERA-40 and the IFS are based on the same version of the IFS (cycle 23r4). Even so the initial analyses of the IFS will differ from the reanalyses because the former is operated at T511 and uses the 4DVAR scheme, which became operational at the ECMWF in November 1997. Evaluation of changes to the PBL model for the IFS are for the IFS cycle 28r4, and thus the statistics of the standard model differ from the statistics of the 23r4 model, which formed the basis of the evaluation in section 3 .

The NNRA is based on a T62, 28 level model, although we primarily analyze fields made available on a slightly coarser, fixed $2.5^{\circ}$, grid at fixed pressure levels. Although the 28-level model consists of 7 levels at pressures greater than $850 \mathrm{hPa}$, the gridded data is only made available at 3 of these levels: 1000, 925, and 850 $\mathrm{hPa}$. For our subsequent comparisons we average the NNRA data over the four grid columns between $29^{\circ}$ and $34^{\circ} \mathrm{N}$, and from $118.5^{\circ}$ to $123.5^{\circ} \mathrm{W}$. Because this region is more extensive than, and biased somewhat eastward of, our study region we examine the sensitivity of our conclusions to the averaging region chosen by also averaging over only the two westwardmost grid columns (i.e., between $121^{\circ}$ and $125^{\circ} \mathrm{W}$ ).

The GFS runs were based on a 42-level model with a triangular truncation of 170 . Forecast variables were provided every $3 \mathrm{~h}$ at nine grid points on a $1.4^{\circ}$ mesh with a center point at $31.23^{\circ} \mathrm{N}, 121.64^{\circ} \mathrm{W}$.

For both NNRA and ERA-40 we calculate the dewpoint temperatures based on the spatially averaged temperatures, humidities, and pressures. 


\section{REFERENCES}

Ackerman, A. S., M. P. Kirkpatrick, D. E. Stevens, and O. B. Toon, 2004: The impact of humidity above stratiform clouds on indirect aerosol climate forcing. Nature, 432, 1014-1017.

Adams, J. C., and P. Swarztruabuer, 1997: SPHEREPACK 2.0: A model development facility. Tech. Note NCAR/TN-436STR, National Center for Atmospheric Research, Boulder, $\mathrm{CO}, 58 \mathrm{pp}$.

Betts, A. K., P. Minnis, W. Ridgeway, and D. F. Young, 1992: Integration of satellite and surface data using a radiative convective oceanic boundary layer model. J. Appl. Meteor., 31, 340-350.

Bony, S., J.-L. Dufresne, H. le Treut, J.-J. Morcrette, and C. Senior, 2004: On dynamic and thermodynamic components of cloud changes. Climate Dyn., 22, 71-86.

Boville, B., P. J. Rasch, J. J. Hack, and J. R. McCaa, 2006: Representation of clouds and precipitation processes in the Community Atmosphere Model version 3 (CAM3). J. Climate, 19, 2184-2198.

Bretherton, C. S., and R. Pincus, 1995: Cloudiness and marine boundary layer dynamics in the ASTEX Lagrangian experiments. Part I: Synoptic setting and vertical structure. J. Atmos. Sci., 52, 2707-2723.

- J. R. McCaa, and H. Grenier, 2004a: A new parameterization for shallow cumulus convection and its application to marine subtropical cloud-topped boundary layers. Part I: Description and 1D results. Mon. Wea. Rev., 132, 864-882.

— Bull. Amer. Meteor. Soc., 85, 967-977.

Caldwell, P., C. S. Bretherton, and R. Wood, 2005: Mixed-layer budget analysis of the diurnal cycle of entrainment in southeast Pacific stratocumulus. J. Atmos. Sci., 62, 3775-3791.

Campbell, G. G., 2004: View angle dependence of cloudiness and the trend in ISCCP cloudiness. Preprints, 13th Conf. on Satellite Meteorology and Oceanography, Norfolk, VA, Amer. Meteor. Soc., CD-ROM, P6.7.

Duynkerke, P. G., and J. Teixeira, 2001: Comparison of the ECMWF reanalysis with FIRE I observations: Diurnal variation of marine stratocumulus. J. Climate, 14, 1466-1478.

Fiorino, M., 2004: A multi-decadal daily sea surface temperature and sea-ice concentration data set for the ERA-40 reanalysis. ERA-40 Project Rep. Series 12, ECMWF, 22 pp.

Garreaud, R. D., and R. C. Muñoz, 2005: The low-level jet off the west coast of subtropical South America: Structure and variability. Mon. Wea. Rev., 133, 2246-2261.

Gentemann, C. L., F. J. Wentz, C. A. Mears, and D. K. Smith, 2004: In situ validation of Tropical Rainfall Measuring Mission microwave sea surface temperatures. J. Geophys. Res., 109, C04201, doi:10.1029/2003JC002092.

Gibson, J. K., P. Kållberg, S. Uppala, A. Nomura, A. Hernadez, and E. Serrano, 1997: ERA description. ERA-15 Project Rep. Series 1, ECMWF, 71 pp.

Goldberg, M. D., 1999: Generation of retrieval products from AMSU-A: Methodology and validation. Tech. Proc. 10th Int. TOVS Study Conf., Boulder, CO, Bureau of Meteorological Research Center, 215-219.

Grody, N., J. Zhao, R. Ferraro, F. Weng, and R. Boers, 2001: Determination of precipitable water and cloud liquid water over oceans from the NOAA-15 Advanced Microwave Sounding Unit. J. Geophys. Res., 106, 2943-2953.

Guan, L., and H. Kawamura, 2003: SST availabilities of satellite infrared and microwave measurements. J. Oceanogr., 59, 201-209.

Kalnay, E., and Coauthors, 1996: The NCEP/NCAR 40-Year Reanalysis Project. Bull. Amer. Meteor. Soc., 77, 437-471.

Kilpatrick, K. A., G. P. Podestá, and R. Evans, 2001: Overview of the NOAA/NASA Advanced Very High Resolution Radiometer pathfinder algorithm for sea surface temperature and associated match-up database. J. Geophys. Res., 106, 91799197.

Klein, S. A., 1997: Synoptic variability of low-cloud properties and meteorological parameters in the subtropical trade wind boundary layer. J. Climate, 10, 2018-2039.

_ , and D. L. Hartmann, 1993: The seasonal cycle of low stratiform clouds. J. Climate, 6, 1587-1606.

Lenschow, D. H., P. B. Krummel, and S. T. Siems, 1999: Measuring entrainment, divergence, and vorticity on the mesoscale from aircraft. J. Atmos. Oceanic Technol., 16, 1384-1400.

Lock, A., 2004: The sensitivity of a GCM's marine stratocumulus to cloud-top entrainment. Quart. J. Roy. Meteor. Soc., 130, 3323-3338.

Lothon, M., D. H. Lenschow, D. Leon, and G. Vali, 2005: Turbulence measurements in marine stratocumulus with airborne Doppler radar. Quart. J. Roy. Meteor. Soc., 131, 2063-2080.

McNoldy, B. D., P. E. Ciesielski, W. H. Schubert, and R. H. Johnson, 2004: Surface winds, divergence, and vorticity in stratocumulus regions using QuikSCAT and ranalysis winds. Geophys. Res. Lett., 31, L08105, doi:10.1029/2004GL019768.

Miller, R. L., 1997: Tropical thermostats and low cloud cover. J. Climate, 10, 409-440.

Minnis, P., D. Young, C. Fairall, and J. Snider, 1992: Stratocumulus cloud properties from simultaneous satellite and islandbased instrumentation during FIRE. J. Appl. Meteor., 31, 317-339.

Norris, J. R., 1998: Low cloud type over the ocean from surface observations. Part I: Relationship to surface meteorology and the vertical distribution of temperature and moisture. J. Climate, 11, 369-382.

, 1999: On trends and possible artifacts in global ocean cloud cover between 1952 and 1995. J. Climate, 12, 1864-1870.

— surface observations. Part III: Relationship to vertical motion and the regional surface synoptic environment. J. Climate, 13, 245-256.

Reynolds, R. W., N. A. Rayner, T. M. Smith, D. C. Stokes, and W. Wang, 2002: An improved in situ and satellite SST analysis for climate. J. Climate, 15, 1609-1625.

Rossow, W., and R. A. Schiffer, 1999: Advances in understanding clouds from ISCCP. Bull. Amer. Meteor. Soc., 80, 2261-2287.

Rozendall, M. A., and W. B. Rossow, 2003: Characterizing some of the influences of the general circulation on subtropical marine boundary layer clouds. J. Atmos. Sci., 60, 711-728.

Savic-Jovcic, V., B. Stevens, and D. H. Lenschow, 2002: Estimating divergence and vorticity from aircraft data in the stratocumulus topped boundary layer. Preprints, 15 th Symp. on Boundary Layers and Turbulence, Wageningen, Netherlands, Amer. Meteor. Soc., 112-113.

Schlax, M. G., D. B. Chelton, and M. H. Freilich, 2001: Sampling errors in wind fields constructed from single and tandem scatterometer datasets. J. Atmos. Oceanic Technol., 18, 10141036.

Slingo, J., 1980: Cloud parameterization scheme derived from GATE data for use with a numerical model. Quart. J. Roy. Meteor. Soc., 106, 747-770. 
Stephens, G. L., 1978: Radiation profiles in extended water clouds. Part II: Parameterization schemes. J. Atmos. Sci., 35, 2123-2132.

, and Coauthors, 2002: The CloudSat mission and the ATrain: A new dimension of space-based observations of clouds and precipitation. Bull. Amer. Meteor. Soc., 83, 17711790 .

Stevens, B., and Coauthors, 2003a: On entrainment in nocturnal marine stratocumulus. Quart. J. Roy. Meteor. Soc., 129, 34693492.

, and Coauthors, 2003b: Dynamics and Chemistry of Marine Stratocumulus-DYCOMS-II. Bull. Amer. Meteor. Soc., 84, 579-593.

— via observations of nocturnal marine stratocumulus. Mon. Wea. Rev., 133, 1443-1462.

_- G. Vali, K. Comstock, R. Wood, M. C. van Zanten, P. H. Austin, C. S. Bretherton, and D. H. Lenschow, 2005b: Pockets of open cells and drizzle in marine stratocumulus. Bull. Amer. Meteor. Soc., 86, 51-57.

Taylor, K. E., 2001: Summarizing multiple aspects of model performance in a single diagram. J. Geophys. Res., 106, 71837192.
Troen, I. B., and L. Mahrt, 1986: A simple model of the atmospheric boundary layer: Sensitivity to surface evaporation. Bound.-Layer Meteor., 36, 129-148.

Uppala, S. M., and Coauthors, 2005: The ERA-40 re-analysis Quart. J. Roy. Meteor. Soc., 131, 2961-3012.

vanZanten, M. C., and B. Stevens, 2005: Observations of the structure of heavily precipitating marine stratocumulus. $J$. Atmos. Sci., 62, 4327-4342.

- B. Stevens, G. Vali, and D. H. Lenschow, 2005: Observations of drizzle in nocturnal marine stratocumulus. J. Atmos. Sci., 62, 88-106.

Wang, J., 2005: Evaluation of the dropsonde humidity sensor using data from DYCOMS-II and IHOP 2002. J. Atmos. Oceanic Technol., 22, 247-257.

_ W. B. Rossow, T. Uttal, and M. Rozendaal, 1999: Variability of cloud vertical structure during ASTEX observed from a combination of rawinsonde, radar, celiometer, and satellite. Mon. Wea. Rev., 127, 2484-2502.

Wood, R., and C. S. Bretheron, 2004: Boundary layer depth, entrainment, and decoupling in the cloud-capped subtropical and tropical marine boundary layer. J. Climate, 17, 35763588 . 